\title{
A JOURNEY THROUGH THE EVOLUTION OF THEORIES AND MODELS OF ADOPTION OF INNOVATIONS (YEARS: 2000 - 2018)
}

\author{
Sylesh Nechully \\ Research Scholar, UPES, Dehradun, India
}

Dr. S.K. Pokhriyal

Professor and Head - Energy Management, School of Business - UPES, Dehradun, India

\section{Dr. Saju Eapen Thomas}

Dept Chair - Marketing, City University College Ajman, UAE

\begin{abstract}
The study furnishes in a nut shell the evolution of diffusion theories and models from 2000 till 2018. Various steps and factors involved are reviewed and consolidated to give scholars a holistic insight to the process of diffusion. The practical implications of these theories/models are also discussed as to how the adoption/diffusion can be accelerated by manipulating the variables. Narrative Synthesis Approach is used to draft this paper. Narrative Synthesis is all about systematically reviewing diverse literature and concluding findings using words and text. Four data bases - EBSCO, Petro One, JSTOR and Pro Quest were used for Literature search. Primary Search was done using the Key words mentioned and its various combinations to identify the relevant theories/models in a particular period and subsequently the name of the authors/theories/models were used to identify the core paper/book. Diffusion literature is very vast. There are umpteen numbers of studies available. None of these models can be generalized. The direction and intensity of impact of factors varies based on context, product, organization, industry and country.
\end{abstract}

Keywords: Innovation; Diffusion; Adoption; Implementation; Technology; Process; Organization

Cite this Article: Sylesh Nechully, Dr. S.K. Pokhriyal and Dr. Saju Eapen Thomas, A Journey through the Evolution of Theories and Models of Adoption of Innovations (Years: 2000 - 2018), International Journal of Production Technology and Management (IJPTM), 9(2), 2018, pp. 31-73.

http://iaeme.com/Home/issue/IJPTM?Volume $=9 \&$ Issue $=2$ 


\section{INTRODUCTION}

OECD (2005) proposes four types of innovation namely (1) Product (2) Process (3) Marketing methods (4) New Organizational methods. Based on where an organization should channelize its resources, Innovation can be divided into (1) Internal Innovation and (2) External Innovation (Blacklock, Westley and McGowan, 2015). Involving internal participants in the process of innovation helps companies to have more control over resources and work environment. There is a contradicting view proposed by (Gabrick, 2010) that internal participants are not able to bring in "fresh air" to the organization. External participants bring with them their experience and new perspectives on problem solving to the organization. Based on source of innovation, categorization can be (1) Manufacturer Innovation (2) End user innovation. End users, eithers firms or consumers improvise on the product(s) or service(s) based on their individual requirements. A standard product or service gets customized based on requirements and this is fed back to the manufacturers. Listening to "Voice of customers" is an excellent source of fresh ideas. Another way of categorization (Lomax, 1997) is based on the impact of innovation to the existing market/industry. (1) Cannibalization (2) Market creation and (3) Competitor disruption (Designorate, 2017). Cannibalization occurs when an innovative product(s) reduces the market of the existing product(s) of the same company. Competitor disruption (Downes and Nunes, 2013 ) is a concept similar to radical innovation where new markets are created due to innovation and current ways of doing things are completely replaced by better process or service. Doblin (2015) expands the concept by adding innovations in “ (1) Business model (2) Networking (3) Channels (4) Brand (5) Customer experience (6) Enabling process (7) Core process". Moore (1991) enriches the innovation literature by adding the concepts of (1) Line extension (2) Marketing Innovation (3) Experimental Innovation (4) Value Engineering (5) Integration (6) Value migration (7) Organic Innovation and (8) Acquisition". Value Engineering is a process of enhancing the value either by increasing the features or by lowering the cost. Value migration is the concept of changing the existing business model(s) to satisfy the requirements of the customer(s) based on the changes in the environment.

It's often the very low success rates of innovation in general that discourages firms to innovate. Success rate of innovation has been a topic of discussion since time immemorial. It's a very controversial topic. Payne (2014) posits that $90 \%$ of the innovations fail in the market. An innovation can have excellent features but it might not be appealing to customer due to sophistication in using or due to lack of aesthetic appeal or the functions may be irrelevant to them or due to cost or fad/fashion factor.

In various papers, we can see the words "Adoption" and "Diffusion" interchangeably used. The researcher also came across many papers where "Diffusion models" used in place of "Adoption" and Vice versa. Actually both these concepts are theoretically different. Adoption is what an organization does and diffusion occurs across organizations. (Glor, 2001). Adoption referrers to the stage of technology selection and utilization by an organization or an individual whereas Diffusion refers to general spread of technology among organizations or Individuals. (Ahsanuzzaman, 2014). Diffusion is more of a supply side role or activity and Adoption is more of a demand side role or activity (Vargas, L.A., 2016). "Adoption of Innovation" is the process by which a particular system accepts something "which they have never used before". Rogers (1983) defines innovation "as the process by which innovation is communicated through certain channels over time among the members of system" (Likar et.al, 2013). (Blumberg, 2016) states that diffusion refers to "how an innovation spread within a group, community or country". Adoption occurs at the individual levels. Individuals can only adopt. In short, diffusion is the process by which an innovation is 
communicated by the innovator to the different members of the system and how the members adopt the innovation. Adoption is the process of procurement and utilization of innovation.

\section{METHODOLOGY}

The Researcher applies a Narrative synthesis approach to review the literature. Narrative synthesis is a process of drawing conclusions from diverse literature using words and texts. Narrative synthesis helps to identify complex interrelationships between various concepts from various sources. Narrative synthesis helps to systematically review the studies already done and add unique original views of the researcher to the existing body of knowledge. Four data bases - EBSCO, Petro One, JSTOR and Pro Quest were used for Literature search. Primary Search was done using the Key words mentioned and its various combinations to identify the relevant theories/models in a particular period and subsequently the name of the authors/theories/models were used to identify the core paper/book.

\section{EVOLUTION}

Wiefel (2002) explained the Technology adoption Life Cycle in his famous book "The Chasm Champion". Technology adoption life cycle helps managers to determine at which stage of the adoption the innovative product is and according develop strategies and allocate resources. An innovative product goes through 6 different stages of product life cycle. (1) The Early market: consists of Technology Enthusiastic and Visionaries. Enthusiast believes that the innovative product is better than the existing product and supports the adoption. Visionaries are people who find innovation as a source of competitive advantage in the market. These both categories of people aggressively adopt innovative technologies. (2) The Chasm: the innovative product encounters a "break" or "pause" in this stage. The pragmatics do not necessarily follow Visionaries unless and until they are $100 \%$ convinced about the benefits of the products. In this stage it is advisable to find niche markets which can be catered easily and success stories in these markets helps innovators to cross the chasm. "Crossing the Chasm" is the most important stage for an "Innovative product". (3) Bowling Alley/Pragmatists: In this stage the product is already catering to the needs of various niche markets. At this point of time, media and market analysts may start showing some interest in the innovation. The "Innovator" is in a "take off" mood to other segments. (4) The Tornado/Pragmatists: In this stage the product is catering to the mass market. The success of the product invites the attention of competitors in the mass market and quality increases and price comes down to capture the market share. (5) Main street/Conservatizes: Most risk averse people. In this stage the "innovation" has reached its saturation point with declining growth rates. Confirmed quality at a reduced price is what appeals to Main Street or conservatizes. The reason for purchasing the innovation will be to avoid a competitive disadvantage or regulatory compliance. In this stage the innovator tries to capture current market or other nice markets by enhancing features or reducing costs further. (6) Total Assimilation/Skeptics: Last stage of product life cycle and in this stage only laggards or skeptics embraces the product. A new "innovation" has already started somewhere and the attention of market analysts and media has completely shifted its focus to that technology. After sales service for existing customers generates some revenue for companies at this stage. 


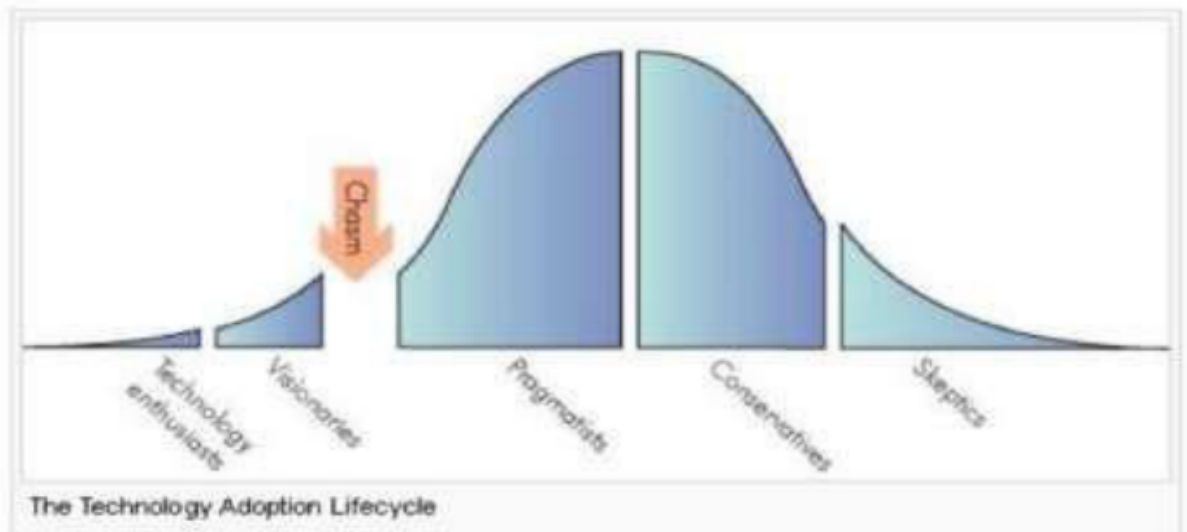

Figure 1 Wiefel's categorization of adopter sets (adapted from Wiefel, 2002)

Product Specific Adoption Potential Model is a survey method developed by Marez (2006) to do the "Pre launch" forecasting and market segmentation for innovative products. This method provides valuable inputs to formulate strategies for various segments.

250 to 10,000 prospects are selected for the survey. Questionnaires regarding the requirement are administered. Questions are asked about the (1) General feature requirements (2) Perceived optimal product (3) Suboptimal product. Optimal products are those meeting all requirements of the customer. Suboptimal products may not meet all the requirements; some features are compromised for affordability. At every question - the respondents are asked to rate on a Linkert scale their propensity to adopt. If we have lot of respondents ready to adopt even a suboptimal product -then we have a successful product. PSA Heuristics are used to segment market into adopter categories based on the questionnaire. Moore (1991) argues that an innovative product can be termed "Successful" if it crosses the "Chasm" between -Early adopters and early majority. This mode helps us to predict whether the innovative product can cross the "Chasm" or not. This concept helps us to analyze the features that can attract the customers, purchasing power of the market and the total market potential for innovative product.
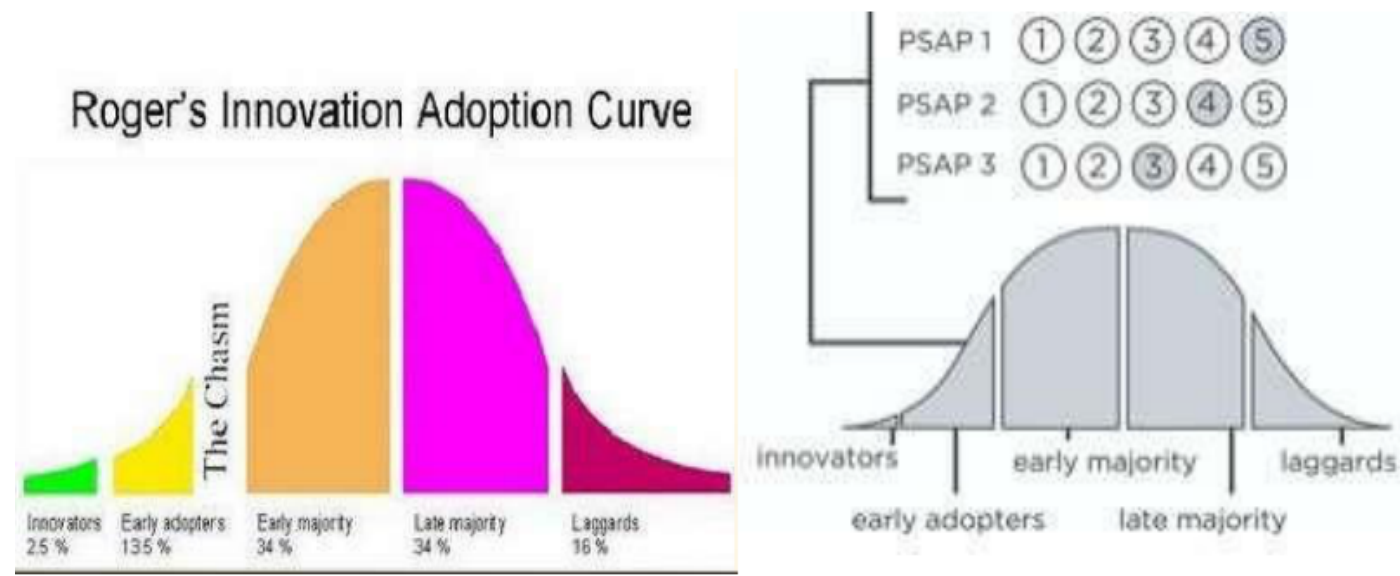

Figure 2 Moore's Concept of The Chasm (adapted from Moore, 1991)

McKeown and Barnett (2012) explain the technology adoption process in Education sector by The Pencil Metaphor. This is an extension of the Technology adoption model (Roger, 1957). In this model - Adoption starts with "Leaders". Leaders are Technology experimenters and they share their experience with others. "The sharp ones" are those who follows the experiences of leaders. They embrace the technology befitting their requirements and reject irrelevant products. "The Wood" are the adopter set who would like to be spoon 
fed. They embrace adoption if coerced by other or if becomes essential. They always look forward to assistance or training on the Technology set up and usage. "The Ferrules" are orthodox set who likes to hang on to "Status Quo". They are very reluctant to change their old ways of doing things. Next comes - "The Erasers". The erasers are the stumbling block to adoptions. They try to stymie adoption at any rate. They acts against the beneficial changes implemented by the Leaders.

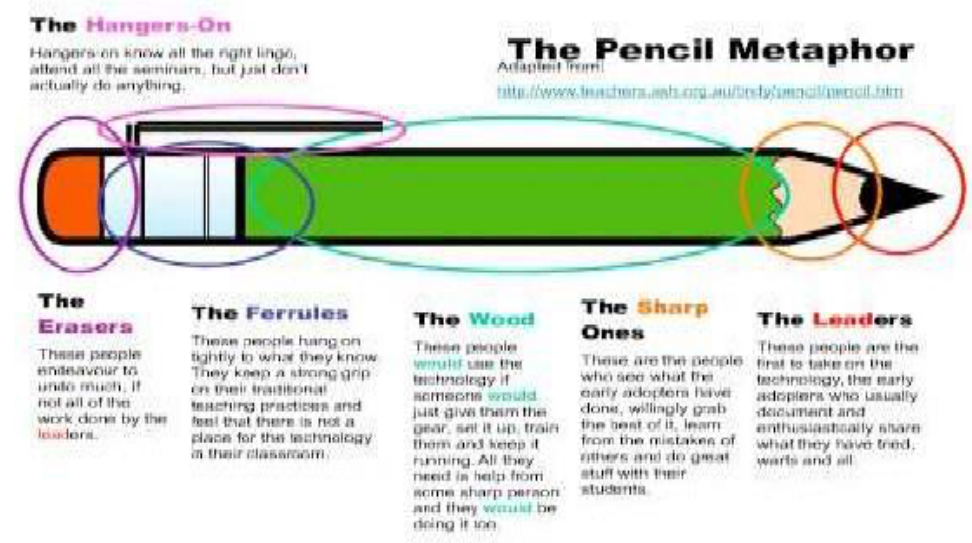

Figure 3 The Pencil Metaphor (adapted from McKeown and Barnett, 2012)

The Bowling Pin Model (2002) explains that a strategy that can be adopted by manufacturers of innovative product is to find a niche market or segment where they can successfully promote their product and then move on to other markets or segments. (Moore, 2002). Initially, companies do not have to introduce most advanced product in the niche market. They have to add features as they progress to other segments based on customer preferences. This model helps to determine the "USPs" required for different segments. The USP applicable to the initial niche market is called "Beach Head".

\section{The Bowling Pin Model}

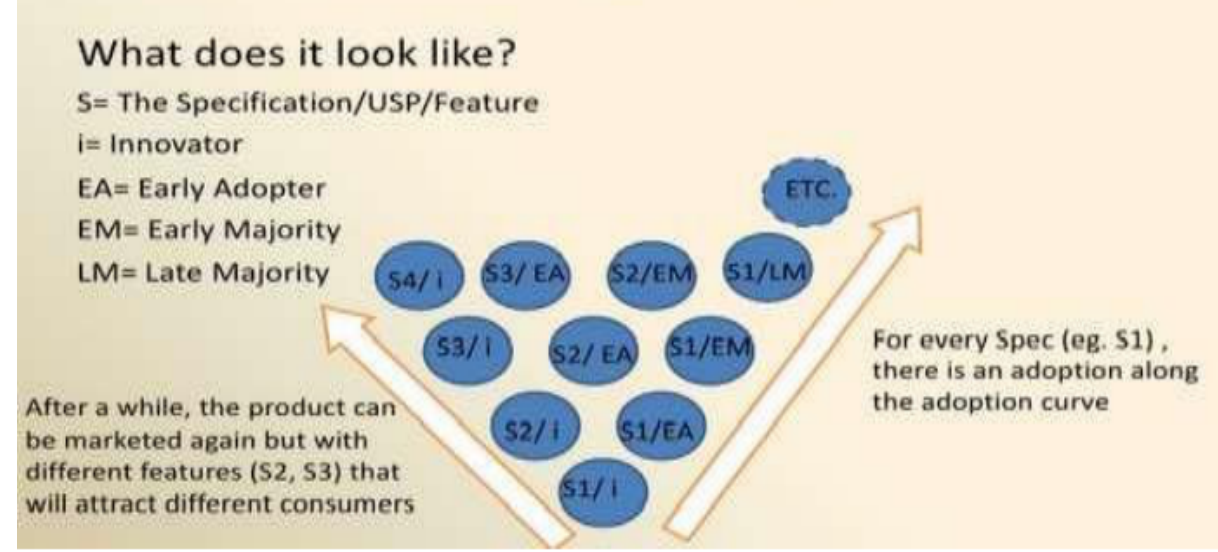

Figure 4 The Bowling Pin Model (adapted from Moore, 2002)

To comprehend the adoption process clearly, we need to combine the "Factor Stream" and "Process stream" of diffusion research. Statnikova (2005) used Kwon and Zmud model of 
adoption as a frame work to study the adoption of IS. Statnikova (2005) tried to explain the factors affecting different stages of adoption. The factors were categorized along 4 dimensions - (1) Organizational (2) User (3) Project (3) Technological. At the initiation stage of adoption, the Organization factors affecting adoption - Organizational climate, Work group characteristics and Job characteristics have to be assessed in details. The Higher satisfaction level with the current system makes the introduction of new systems extremely difficult. Positive attitude towards innovation and Computer literacy strongly influences the initiation stage. Adoption stage is affected by management commitment, Resource availability and User involvement. Adaptation to the new system depends on Management commitment, Project uncertainty, Personal innovativeness and Project team composition. Facilitating conditions and Relative advantages of the technology compared to the existing one-accelerates the acceptance process. The main disadvantage of this model is that it does not take in to account the Satisfaction/Feedback derived from the implementation which will ultimately lead to continued usage or total abandonment. Statnikova (2005) Views adoption of innovation as an "Organization change process". "User" related factors affect all four stages. "Project" related factors affect three stages namely - adoption, adaptation and acceptance. "Technology" related factors affect adaptation and acceptance. "Organizational” factors affect only Initiation stage.

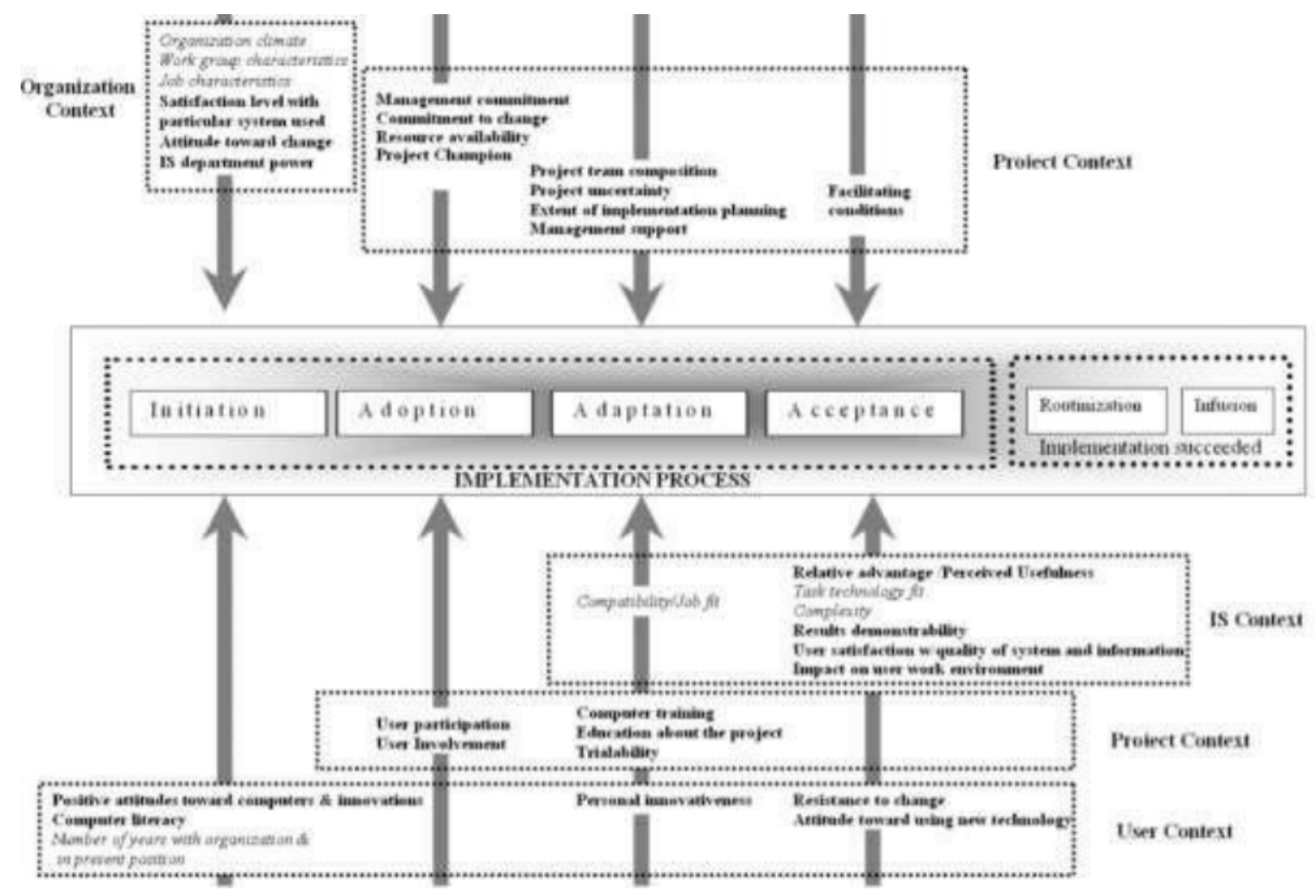

Figure 5 Statnikova Frame work of adoption(adapted from Statnikova, 2005)

Consumer Innovativeness - Alliance Image Mode of product adoption (Christia, 2000) posits that the adoption of new products depends on two factor (1) product category specific innovativeness and (2) General consumer innovativeness. The effects of these two categories are moderated by the Alliance image of the companies. Consumer innovativeness refers to the propensity of some individuals in a particular market to experiment with new products/technologies (Hirschman, 1980). Consumer innovators constitute a minority in the market - around $2.5 \%$ only (Spears, 1998). These consumer innovators constitute the opinion 
leaders of a particular market (MacFie and Jaeger, 2010). Companies have to target these innovators to accelerate adoption (Robertson, 1967)

Consumer Innovativeness can be divided in to products category specific and general consumer specific. (Armstrong, 1975). Product category specific innovators searches for information relevant to a specific product category and becomes knowledgeable in that category. (Kirton, 1976). General customer innovativeness is a trait influenced by demographic characteristics and psychological conditions of the customer. Innovators tend to be young, financially sound and held in high esteem by the society. (Roger, 1962). Customers with this trait do not restrict their interests to one specific category but they are very inquisitive and spread interests to many product categories. (Wells and Tigret, 1971). They are normally risk takers (wedel and Kamakara, 1999).

Consumer Innovativeness - Alliance Image Model of Product Adoption

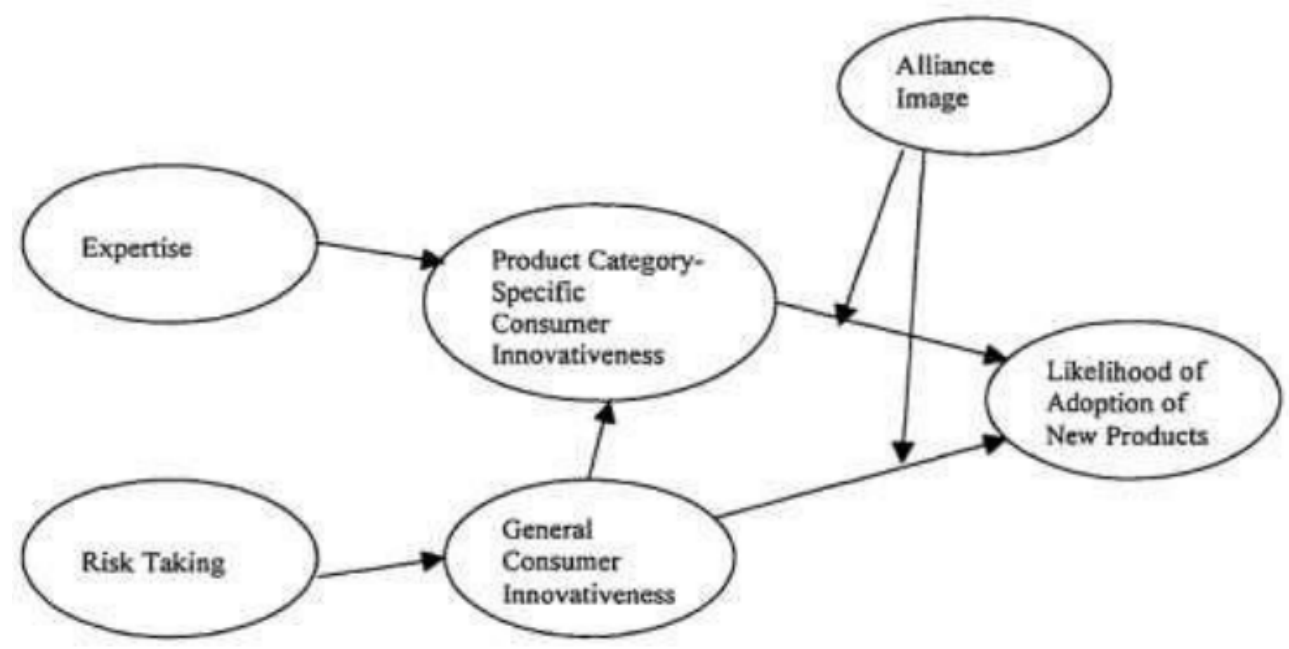

Figure 6 Consumer Innovativeness - Alliance Image Model (adapted from Christia, 2000)

Alliances are formed in today's competitive market to form synergy. (Sawhney, Verona and Prandelli 1990). New product development and marketing requires lots of resources and not many companies possess all these resources. So a strategy is to share among "Haves" and "Have nots". Companies entering into alliance should be reputed and this reputation results in speedy adoption of the product. Most often customers give more weightage to company reputation than the features of the product itself while making purchases (Yoon and Tello, 2008)

Botha and Atkins (2005) states that both contextual factors and personal factors affects the process of adoption. Adoption process starts with being prospect ignorant - "Pre Contemplation stage" about the innovation (Prochaska, 1992). The individual or organization becomes aware of the innovation through various channels. The innovation may be rejected at the stage. Otherwise, proceeds to the next stage. Individual/Organization develops interest towards the innovation and make comparison with the existing solutions or alternatives available in the market. He may reject at the stage. If not, he may want to have hands on or field trails with the innovation on a small scale. If he is satisfied, he may adopt the innovation or else rejects. Even after adopting the innovation - there are chances of prospect abandoning innovation mostly due to contextual factors. 


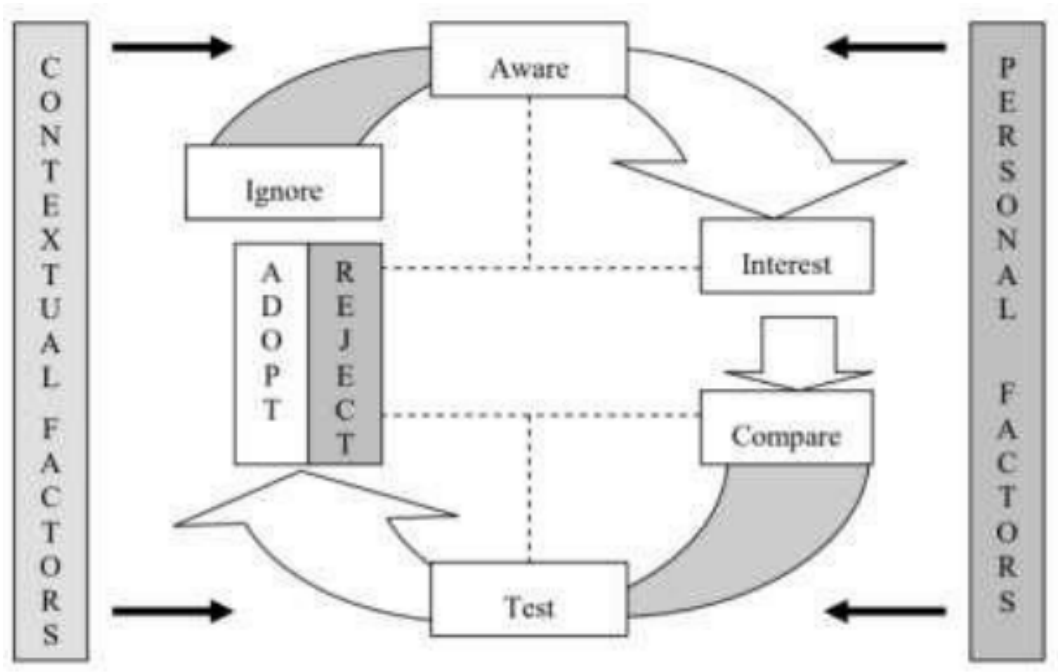

Figure 7 Botha and Atkins Model (adapted from Botha and Atkins, 2005)

Based on how a product satisfies "Customer needs" - it can be categorized in to (1) Desirable (2) Feasible (3) Salable (Shane, 2008).

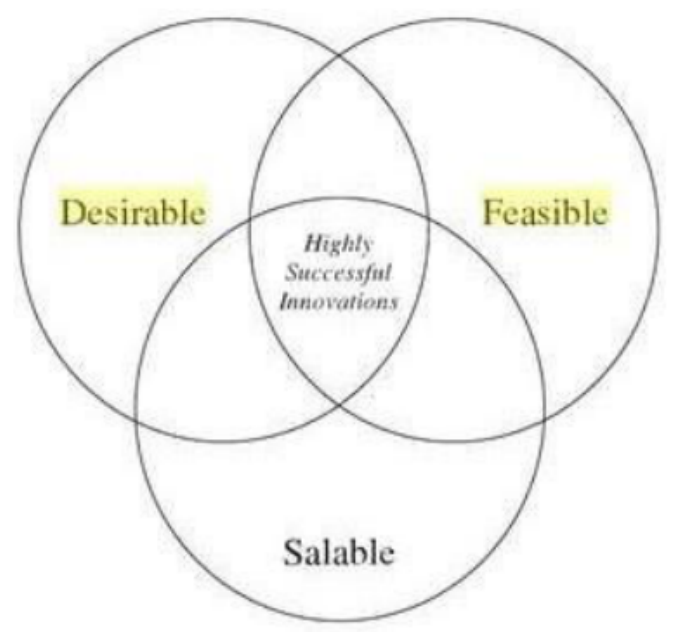

Figure 8 The Innovation Space Concept (adapted from Shane, 2008)

"Desirable" product satisfies all the requirements of the customers giving them utmost satisfaction. It is a concept of "Ideal Product". But in reality it might not be "Feasible" to fabricate due to either resource constraints or socio-economic factors. So some of the features of the products will have to be compromised to make it feasible to fabricate. "Salable" product can be sold in market.

For an innovation to be successful it should have features which are desirable to customers, feasible to manufacturers and are marketable with in the socio-economic-legal context of market. Successful innovations happen at the intersection of "Desirable", "Feasible" and "Salable". Most of the companies are "Product driven" rather than "Customer driven". "Product driven" companies manufacturer feasible products and spend huge amount on advertisements to market the product. This is "Push strategy". "Customer driven" companies adopt a "pull strategy" by manufacturing "Desirable-Feasible- Salable" product.

SAMR Model of Technology Adoption (Puentedura, 2006) explains how innovative technologies can be adopted in education sector to make the student teacher interaction more 
effective/lively/interesting. It suggests four levels of adoption of innovative technologies to amplify the learning experience ( Puentedura, 2006).

First two steps are Enhancement steps and last two steps contribute to complete transformation - the way things are done. Innovative technology substitutes the existing technology (Substitution) followed by functional improvements (Augmentation). Then the innovative technology helps to redesign the tasks (Modification) followed by redefinition of tasks - to create entirely new tasks which were inconceivable had it not been the implementation of innovative technologies (Redesign). The Frame work helps teachers to identify and integrate the appropriate technologies available in the market to enhance the learning experience.

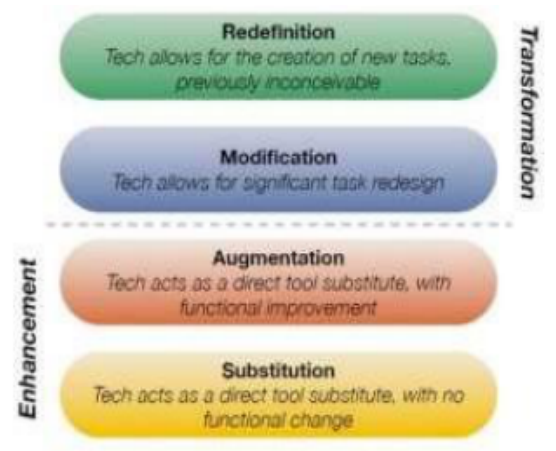

Figure 9 SAMR Model of Technology Adoption (adapted from Puentedura, 2006)

ARCS Model of Adoption (Keller and Suzaki, 1988) suggests that an individual will do a particular task if and only if he thinks that he can complete the task successfully and that the task can satisfy his personal needs. This is true in the case of adoption of innovative technologies as well. An individual/organization will adopt a new technology if and only if the individual/organization feels that the technology can be implemented successfully and the technology meets the needs of individual/organization. ARCS model put forward four factors that can affect the motivation to learn new things or to do new tasks. (1) Attention: The new task/Technology should attract the attention in terms of providing stimulation or variety (2) Relevance: The users should feel that the innovation is relevant for satisfying their needs (3) Confidence: The user should be confident about their ability to master the new technology (4) Satisfaction: The innovation should ultimately satisfy the needs of the individuals/organization.

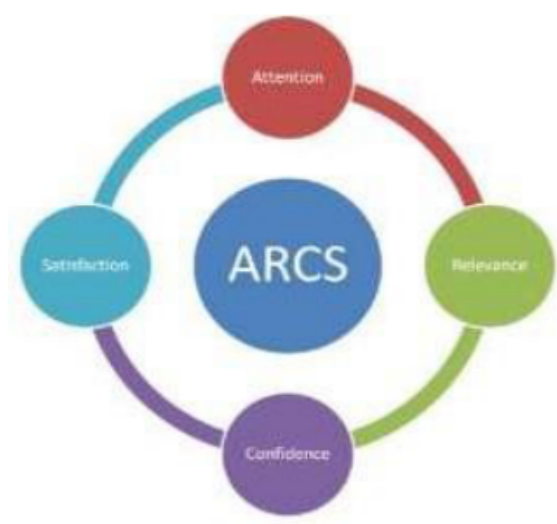

Figure 10 ARCS Model of adoption (adapted from Keller and Suzaki, 2014) 
Ngambi and Bozalek (2013) formulated Wheel Model of Innovation to explain the diffusion of emerging technology in education sector. Leadership plays an important role in diffusion of emerging technologies. The formal leaders - administrators in the senior most management positions can use informal leaders or opinion leaders to facilitate the diffusion of emerging technologies. The opinion leaders are normally senior faculty members. Senior management should enlist the support of Opinion leaders for speeding up adoption process.

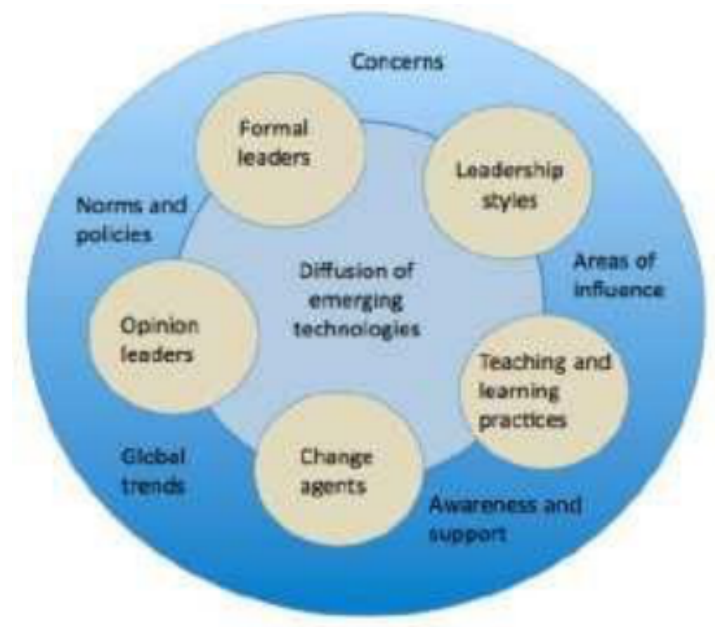

Figure 11 Wheel Model of Innovation (adapted from Ngambi and Bozalek, 2013)

There will be "Pockets of Innovation" in all organizations (Vogel, 2014). "Pockets of innovation" are those people who are ready to experiment with innovation. Opinion Leaders and Innovation pockets might not be the same always.

Coakley and Randall (2007) defines two styles of leadership (1) Transactional (2) Transformative. Transactional leadership uses rewards to motivate employees or disciplinary action for compliances. This leadership is often termed as "Shortsighted". The main objective of this leadership is to facilitate normal day to day operations without any interruptions. Transformational leadership goes beyond managing day to day activities. Transformational leadership views things in longer perspective. Transformational leadership takes performance to the next level by fostering team work and providing opportunities for professional and personal development. This leadership is often termed as "Farsighted". Transactional leadership is required to continue with the day to day operations and transformational leadership is required to elevate the performance to the next level.

The concerns regarding the new technology can be eliminated by (1) providing sufficient training opportunities (2) eliminating role ambiguity (3) communicating the advantages to employees. The adoption should start with "Pockets of innovation" and gradually spread in the organization with the endorsement of opinion leaders. Top management can facilitate the adoption by changing the Norms or policies of the organization.

Market percolation can be defined as the process of percolation of product, belief or information through a network of interconnected clusters in the market. The influence of Heterogeneity on diffusion was explained based on Market Percolation Theory. (Goldenberg, Libai, Solomon, Jan and Stauffer, 2000). Market percolation theory explains the formation and behavior of interconnected clusters in the market and the influence each cluster exerts on another. (Stauffer, Dietrich; Aharony, Anthony, 1994). In a market, the customer can be grouped in to clusters based on a "Perceived Expectations" about the products. Different groups will have different "Perceived Expectations". The concept of Percolation Threshold is a concept in mathematics which can be borrowed to explain the formation of clusters. "Percolation Threshold" is a bench mark of expectations which a product should meet for the 
formation of clusters. If the quality of product is greater than that of Percolation threshold, the interconnected clusters will form. Below the Percolation threshold, interconnected clusters will not form. Clusters are well interconnected through various channels. Each cluster influences its neighboring clusters. Diffusion of innovation is affected the interactions within and between the clusters. One persons in a cluster can influence other neighbors in the same cluster, likewise one cluster can put pressures on the neighboring clusters. Baptista (2000) examined the diffusion patters of Microprocessors and concluded that regional difference contributes to diffusion. Wareham, Levy and Shi (2004) used "Heterogeneity" as a base to study the diffusion patterns of Internet and $2 \mathrm{G}$ mobiles in US Market.

Wareham, Levy and Shi (2004) argues that heterogeneity in socio-economic factors like income, Jobs and Areas of living affects the adoption. Surprisingly it was found out that "African Amercains" who are the under-privileged class in US buys more mobiles than their counterpart because they did not have access to internet and they found mobile as a medium to access the internet.

Gladwell (2000) argues that ideas and messages passes through customers in the same way a disease spreads in an area and coined the concept "Social epidemic". An Idea or message becomes a "Social epidemic" if it crosses a "threshold point" called "Tipping point" beyond which it spreads like a wildfire.

Gladwell (2000) states that the social epidemic is affected by (1) The Law of few (2) The Stickiness Factor (3) The Power of context. "Law of few" describes that the spread of ideas and messages are initiated by a "Niche" in the market categorized as (1) Maverns - who is the "brain" behind the idea (2) Connectors - who spreads the message (3) Sales Men - who motivates others to act on the ideas. The Stickiness Factors refers to the relevance of the message to the customers. If the customer perceives the message irrelevant, he will discard it. The Power of context refers to the favorable factors in the environment for the customers to act up on the message or idea.

According to this theory, there are outstanding people in the market who are capable of starting the epidemic, what the companies have to do is to find out the outstanding people and target them. Gladwell states that "Mavens" are the authorities of knowledge in the market and they are optimistic people who are always ready to impart information to others. At the same time "Mavens" will not be well connected. Here comes the relevance of "Connectors". Connectors are people with special abilities to make friends with lot of people in the society. "Connectors" helps "Mavens" to spread the message in the market. Ultimately the message about the innovation reaches the target audience. But "Connectors" May not have the ability to convince the target market about the benefits of the innovation. "Sales men" do the act of convincing the prospect to elicit a buying behavior.

Hodas and Lerman (2014) proposed Integrated Cascade Theory to explain the information spreading behavior of customers. Hodas and Lerman (2014) States that the likelihood for a person to copy a message or information depends on the number of exposures to that information. The study also proposes that the likelihood to spread an information/behavior depends on the feedback as to how many of his friends have already spread it. Frequent exposure to messages or information or advertisement and regular interactions with adopters increases the likelihood for adoption or rejection of innovation. Every exposure or interaction increases the knowledge base or perception about the innovation.

Dekimpe, Parker and Sarvary (2000) put forward a "Coupled Hazard Model" to explain the process of Diffusion of Innovative Technologies in various countries. "Network externalities" and the "Presence of a central decision maker" accelerate the adoption process. The existence of a large base of customers using a same/similar product increases the value of a product to a customer having the same/similar product. (Shapiro and Katz, 1985). Network 
externalities creates standards or certain regulation for the entire country. The existence of a central decision maker in a country like "Department of Science and Technology" to promote these technologies can speed up the adoption.

Coupled Hazard Model based on Rogers model (1962) divides the country specific diffusion into two stages (1) Implementation stage - Time between first availability and First usages in a country (2) Conformation Stage - Time between first usage and Complete adoption or substitution. The model posits that four factors affects the diffusion of technology

(1) Economic (2) Social/Demographic (3) Installed Base (4) International experience factors.

Wealth enables a country to take risks regarding "Innovations". The speed of diffusion is faster in developed countries. (Antonelli, 1993; Helsen, Jedidi and DeSarbo, 1993). Social/Demographic heterogeneities retards adoption (Gatignon and Robertson, 1985). Consensus and coordination in countries helps to tackle the problems of heterogeneity. The size of installed base creates an "Inertia effect" to continue with the same technology. Bigger the size, the bigger the replacement cost of new technology. (Antonelli, 1993). Larger installed bases require more coordination from the adopter set to change the attitude towards technology. Larger installed base creates standards in the country (Shy, 1996). Due to network externalities of customers across borders, adoption by countries in the international scenario, puts pressure on other countries also to adopt. (Andersen, 1996). Late adopting countries can depend on the experience of early adopting countries and the uncertainties regarding the technologies are also reduced substantially. Technology diffuses faster in late adopting countries (Takada and Jain, 1991)

Opposing Forces Diffusion Model (Myers and Oliver, 2001) explains that the process of diffusion is affected by two forces (1) Provocation - the force which encourages innovation (2) Repression - the force which inhibits innovation. Diffusion of innovation is affected by the diffusion of forces of Provocation and Repression. Forces of provocation diffuse when the customer becomes convinced about the benefits of a particular action and considers only those actions pertinent/appropriate in a particular context. Provocation accelerate the diffusion process. Forces of repression diffuses when customer feels that an action is inappropriate in a particular context due to its inability to produce the desired result. Past success/failures, Inputs from friends/colleagues, Factors in the environment and individual/group agendas results in "Provocation" and "Repression". Mathematically "Diffusion at any point of time" is a function of difference of Provocation and Repression at that particular point of time where Provocation $>$ Repression for diffusion to take place.

Customer Road Mapping is a process by which the key needs of the customers are identified and selected for innovative products (Sandia, 2004). Sandia (2004) has developed four sets of "Universal Need" dimensions of customers namely (1) Functionality, (2) Form,

(3) Usability, (4) Cost. These dimensions help to bench mark and compare various alternatives available in the markets.

Consumer Behavior Theory states that adoption of innovation depends on three factors (1) Level of customer involvement (2) Efforts put in (3) Brand loyalty. Higher levels of I nvolvement and efforts are required to adopt a complex product (Kaine, Beswell and Linehan, 2004). Brand loyalty encourages an individual to try an innovative product from a brand he is committed to even without evaluating the brand. (Assael, 1998). High risk decisions require higher levels of involvement and efforts. Routinely purchased, inexpensive materials require only low level of involvement for adoption. CBT proposes a frame work to understand the decision making process for various types of products which requires different levels of involvement/Efforts.

Normalization Process Theory (May, 2009) proposes a frame work to understand the adoption of new technology in an organization. It is the complex interaction of various 
actors/employees, procedures and statutory requirements which facilitates the adoption of technology in an organization. This theory helps us to understand how different employees behave or interact, under a particular context for the successful adoption of the new technology. This model was based on the studies done in health care field.

May (2009) posits that the complex intervention or interaction between - the objects, actors and contexts and leads to the adoption of technology in an organization. Employees of the organization are the actors. It can even be various groups with specific interests. Procedures or systems in an organization are the Objects. Internal and externals factors specific to organization, which facilitates or restricts the adoption process are the Contexts.

The fashion and then abandon by performance theory proposed by Strang and Macy (2001) posit that the customer does not always follow "Economic Benefit" theories of adoption. They make choices based on the opinion from their colleagues or their own past experiences with the company. "Success stories" in the market can have a significant impact on the adoption of innovation. A times, due to faster rate of adoption, the adoption of innovation becomes hyped too much and will become a "Fashion" in the particular market. This is very much applicable in Mobile phone market. I-phones or androids are used by many people due to this "Fashion" effect not due to its utility of all features. The product becomes a "Status Symbol". Even a product with greater utility gets abandoned due to this "Fashion Effect" for a product with lesser utility. Moreover, the individuals "after purchase experience" with the product also leads to abandonment of innovation.

Wang and Li (2010) enriched the Theory of Performance and Legitimacy by adding one more component - fashion to explain the adoption process of early, middle and late adopters. Wang argued that the diffusion is affected by (1) performance for early adopters (2) fashion for middle adopters and (3) legitimacy for late adopters. The performance fashion legitimacy theory explained the diffusion process of middle adopters as well. The element "Fashion" accelerates the process of adoption from Early to late adopters through middle adopters. (Epstein, Sanders and Sheldon, 2009)

Varian Rule states the easiest way to predict future trends is to observe rich people - what they buy and use, the middle class will follow the same/similar in 10 years and further 10 years down the line, poor people also adopt something similar (Varian, 2011). This rule states that when an innovative product is introduced in the market, it is considered as a "luxury" item and when the advantages of the product is understood, and the price is reduced due to competition and economies of scale, middle class people adopt it followed by poor people. By looking at what the rich people use today, we can forecast what middle class people and poor people use in the future. As the time passes by, the product becomes accessible to all people in the society.

Wenger, White and Smith (2009) describes that in all markets or segments there might be some people who are well versed with the requirements of that particular market and they are also thorough with the technology to solve them. Market look at them as experts and seek advises from them regarding new products/technology. These people are called "Technology Stewards". Technology stewards are open to innovation and they recommend innovation to others in the market if it offers substantial benefits over other products. The companies with innovative products should first convince the "Technology Stewards" to speed up adoption rate. Joshi and Sharma (2007) Segment Market in to two categories (1) Influencers (2) Imitators helps to analyze the process of diffusion in a better way. Influencers affects the Imitators for adoption not vice versa. Influencers can be Technology stewards or Opinion leaders or Reference groups.

Mental Model of Innovation (2012) is the leadership style of Steve Jobs to convince employees or customer about an Innovation is termed as Mental Model of Innovation (Kaipa, 
2012). Studies on Steve Job's working style lead to the concept of "Reality distortion field". Steve Jobs had the unparalleled ability to distort the ground realities several times till the employee or customer gets into his mental model. When the employee or customer gets into the mental mode of Steve jobs, they view technology or solutions through the perspective of Steve Jobs. Steve Jobs used to go on "Re-phrasing" the reality or situation or solution, till he convince the target. Different lines of arguments will be used to convince the Target. "Rephrasing" changes the conviction of what is good and what is bad, What works and what does not work? Re-phrasing or Re-framing helps the customers to view the reality from a new perspective about the advantages of innovation.

This "Art of Re-framing" or Reality distortion helped Steve to get what other thought impossible to achieve with iphones. iphone is an example of "Re-framing" the concept of what a mobile phone could be - a mobile phone without a key pad which was an innovation in 2007. Within five years iphone proved to be the most successful smart phone in the market. Reframing is the key to business model innovation. First stage is Reconceptualization or reframing helps the concepts to get noticed in the market. Second stage is making a frame work in the reframed context for making money. Last stage is to introduce an innovative product - give life to the concept in the reframed context which attracts customers.

Lehman and Weinberg (2000) studied the relevance of timing for the adoption of sequentially released products across various channels of distribution. According to this study, there is a "most favorable" time to release these products. The time gap between two incremental innovations must not be too long. Otherwise the customers will be "bored" using the same products or competitors introduces new products to the market. This is the strategy followed by the Smart Mobile manufacturers. Every six months/one year, mobile manufacturers introduces new models to the market - with some new features added. Another important concept emerged from this study is that the success rate of the initial product affects the success of other products released in sequence.

Parmentola, Simoni and Tutore (2015) Identified general barriers to diffusion of innovation and explicitly linked them to various "Innovation policies"

\begin{tabular}{|c|c|}
\hline $\begin{array}{l}\text { Barriers to technology } \\
\text { diffusion }\end{array}$ & Policies \\
\hline Cost of technology & Consumer tax deductions \\
\hline \multirow{2}{*}{$\begin{array}{l}\text { Bartiers to technology } \\
\text { diffusion }\end{array}$} & Policies \\
\hline & $\begin{array}{c}\text { Subsidies \& grants to technology acquisition } \\
\text { Direct capital subsidies } \\
\text { Concession } \\
\text { Financial support }\end{array}$ \\
\hline Searching costs & $\begin{array}{l}\text { Information provision policies } \\
\text { Co-promotions } \\
\text { Definition of technological standards } \\
\text { Identification of key adopters }\end{array}$ \\
\hline Learning costs & $\begin{array}{l}\text { Incentives to the formation of partnerships between } \\
\text { adopters and technology providers } \\
\text { Academic and public-funded R\&D }\end{array}$ \\
\hline $\begin{array}{l}\text { Switching costs \& } \\
\text { opportunity costs }\end{array}$ & $\begin{array}{l}\text { Consumer tax deductions } \\
\text { Switching technology subsidy } \\
\text { import substitution policies } \\
\text { Financial support }\end{array}$ \\
\hline $\begin{array}{l}\text { Network externalities \& } \\
\text { transition costs }\end{array}$ & $\begin{array}{l}\text { The promotion of inter-firm networking } \\
\text { Definition of technological standards } \\
\text { Incentives to the formation of partnerships between } \\
\text { adopters and new partners }\end{array}$ \\
\hline
\end{tabular}

Figure 12 Adoption barriers (adapted from Parmentola, Simoni and Tutore, 2015) 
Timing of "Innovation policy" and the category in which the policy is introduced affects the adoption rates. If Innovation policies like subsidies exist for a long period of time, there are chances that the customer will delay the purchase decision for further subsidies. If the policies are introduced in the early adopter segment to attract more customers, the early adopters will be reluctant to adopt the innovation for fear of loss of "First mover advantages" (Stoneman and Diederen, 1994).

Dust and Min (2008) emphasizes the importance of variable "Time Consciousness" in making decisions regarding new products. Time is a scarce resource and execution of a particular thing or in daily walks of life - individuals will have "Time budgets". So individuals prefer a product which can be used to achieve their objectives with in the specified "Time budget". The aspects of "Quickness and Convenience" are highlighted in this study (Bosque and Herrero, 2008).

Schmidt and Porteus (2000) explained the process of diffusion in the context of two competing products either introduced by the same company or different companies. This model introduced a concept called "reservation price". Reservation prices is the summation of all benefits delivered by the features of the product. "Surplus" is the difference of "Reservation Price" and "Sales Price". In the context of competition, the customer selects a product with "highest surplus".

Lotka-Volterra equation (Sprott, Wildenberg and Azizi, 2005) explains the effects of competition of two "innovative" products on adoption of both products. The manufacturer of these products tries to attack each other for market share and there by slows adoption process. Ultimately the Fittest of the two survives. (Gregg, 1964)

Mathematically the model can be expressed as follows.

$$
\begin{aligned}
& x(t+1)=\frac{\alpha_{1} x(t)}{1+\beta_{1} x(t)+\gamma_{1} y(t)}, t=1,2, \ldots, n-1 \\
& y(t+1)=\frac{\alpha_{2} y(t)}{1+\beta_{2} y(t)+\gamma_{2} x(t)}, t=1,2, \ldots \infty, n-1
\end{aligned}
$$

Where $\mathrm{x}$ and $\mathrm{y}$ are competing products, $\mathrm{a}=$ logistics parameter, $\mathrm{b}=$ Imitation parameter, $\mathrm{c}$ $=$ Interaction parameter.

Schmidt and Porteus (2000) introduce two "encroachment" strategies for introduction of innovative products. (1) High end encroachment (2) Low end encroachment. "Encroachment" in general is the process of attacking and capturing the existing market of a product by an innovative product. High end encroachment is the process of taking market share from an existing product by introducing a product with modified or additional features. (Incremental Innovation). Low end encroachment is the process by which the market share is taken from an existing technology by entirely new technology. (Destructive innovation). In fact it is a process of creating a new market by making the existing technology obsolete.

Another concept introduced is "Degree of Innovation". Degree of innovation is a measure of product superiority. "Degree of innovation" depends on all aspects of the products. Higher values demonstrates a superior innovation.

Schmidt and Druehl (2005) explain that the reservation price is affected by advertising or word of mouth publicity. Advertising or word of mouth publicity can increase or decrease the reservation price. The cost of production and purchasing power of customer changes with time which in turn can facilitate diffusion and substitution. So there are many strategies a manufacturer can follow - either become a cost leader or differentiate in terms of product features. 
Modis and Konstandopoulos (2003) explain how competition between two innovations can influence the growth of each innovation. There are six ways to influence the adoption of innovation. (1) Pure competition (2) Predator - Prey competition (3) Symbiosis (4) Parasitic (5) Symbiotic (6) No Competition.

Pure competition refers to the instances of innovations competing for the same resources in the market and the mere existence itself is a threat to the competitor. Symbiosis refers to the instance where the association between two innovations is beneficial to each other. Parasitic refers to the situation where the sale of one product is dependent on the sale of other product but these sales will not inhibit or accelerate the growth of other product. Symbiotic refers to the instances when the mere existence of one product threatens the survival of other product. Tall Plant obstructs the sunlight and stymies the growth of short plant. No competition refers to instances where two innovations do not affect each other.

Tellis and Stremersch (2002) studied the diffusions of Automatic Washing machines and Radios in the early twenties and found out that Radios diffused faster than Automatic Washing. He categorized all innovations into two to describe the speed of diffusion (1) White goods (House hold appliances) (2) Brown goods (Entertainment appliances). Tellis and Stremersch (2002) posits that Brown goods diffuse faster than white goods because Brown goods enhances the "Status levels" and they do not have easy substitutes. Radios were categorized as brown goods for which substitutes were not available in 1920s. Automatic washing machines were categorized as white goods due to its easy substitutability with manual washing machines.

Venkatesh and Davis (2000) added two process to the Original TAM (Davis, 1989) model. (1) Social Influence Processes (2) Cognitive Instrumental Process and proposed TAM 2 model. These two dimensions are very vital to understand the adoption of technology by the customer. He has used three variables to explain social influences - Subjective Norm, Voluntariness and Image.

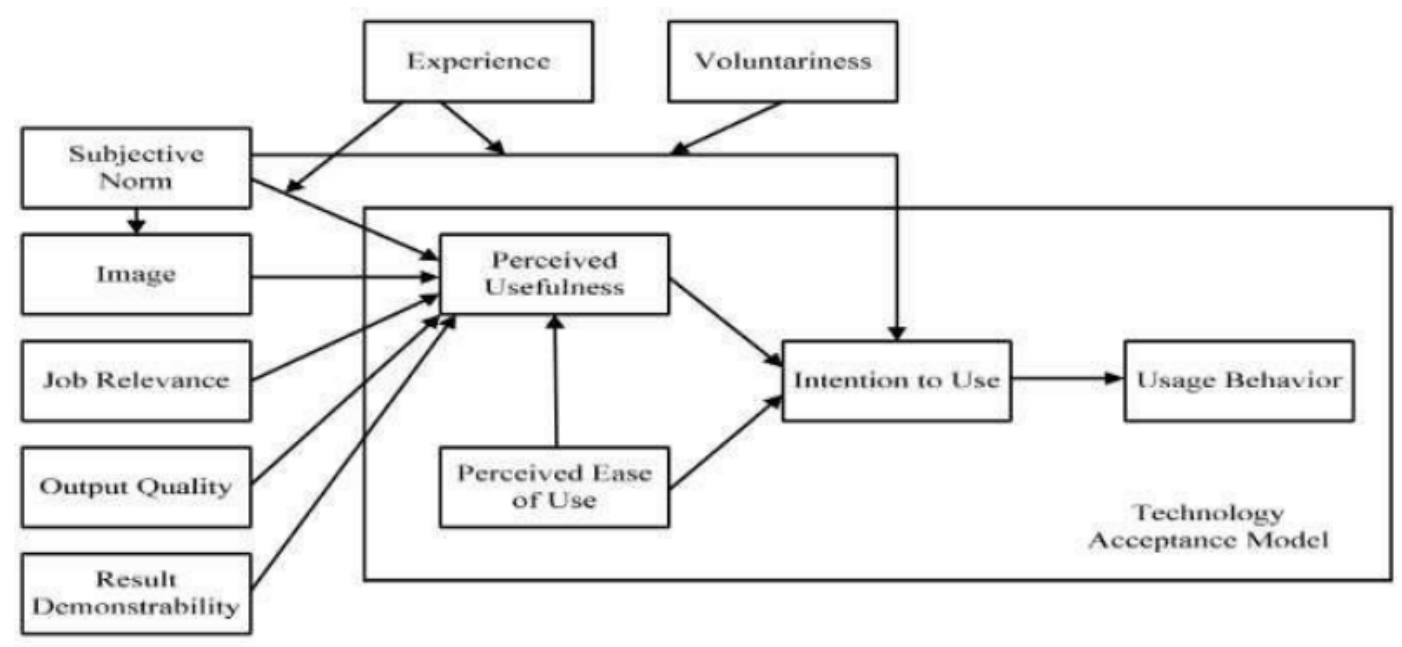

Figure 3. Technology Acceptance Model 2 (TAM 2)

Source: Venkatesh and Davis (2000)

Figure 13 TAM 2 (adapted from Venkatesh and Davis, 2000)

Subjective norms refer to the degree of belief about the appropriateness of an action based on the inputs from a group close to him. It affects the usefulness and attitude to use the instrument. Voluntariness refers to the extent to which a customer finds a particular action not compulsory to be performed. Image refers to the belief of an individual that the action can 
enhance his job performance. Subjective Norm and Image are the key factors to Perceived usefulness whereas Voluntariness moderates the effect of Subjective Norm on Intension to Use

Cognitive Instruments Process - refers to the "mental impression" formed by the customer about the product/technology. It is affected by four variables - Job relevance, Output quality, Result demonstrability and Perceived ease of use.

Job relevance refers to importance assigned by the customer to the product to carry out his daily routines. Output quality explains the after effects of the equipment usage. Result demonstrability refers to the ability of the product to replicate the promised bench mark in actual settings. All these three variables have an impact on the perceived usefulness of the product.

Another variable - "Experience" moderates the effect of Subjective norms on Intension to use and Perceived Usefulness. This effects of "Experience" is predominantly evident for sophisticated technologies. The experience can be divided in to three - Prior to implementation, during implementation and after implementation. Most important is the Experience after implementation. If this is good, even if the other two stages are satisfactory, it will get compensated.

Technology Readiness Index Model (Parasuraman, 2000) posits that negative and positive technology related beliefs influences adoption of innovation. The intensity of these co existing beliefs varies among individuals. Parasuraman (2000) categorizes these beliefs along four dimensions (1) Optimism, (2) Innovativeness (3) Discomfort (4) Insecurity. Optimism and Innovativeness are accelerators of technology adoption and Discomfort and Insecurity are Inhibitors. A high score along Optimism and Innovativeness dimension enhances technology adoption and high score on discomfort and Insecurity dimensions inhibits adoption. Technology readiness is defined as the people's tendency to adopt innovative technologies to reach their goal.

UTUAT (Davis, et al., 2003) is a further refinement of TAM 2 model. He added additional four variables which can have a significant impact on the Behavioral Intension. (1) Facilitating Conditions (2) Hedonic Motivation, (3) Price Value (4) Habit.

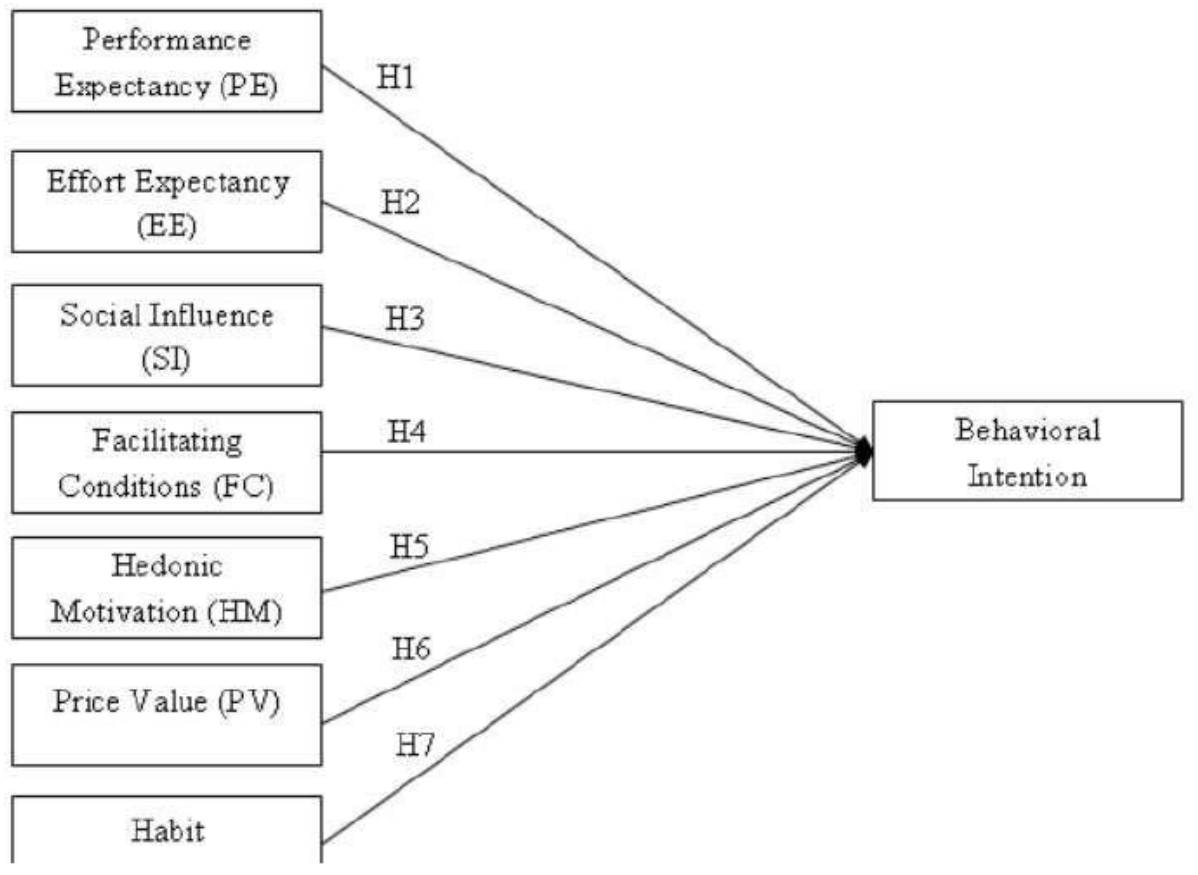

Figure 14 UTUAT Model (as adapted from Davis et. Al, 2003) 
Facilitating Condition refers to the necessary infrastructure required for the successful adoption of the technology. Not only the infrastructure, if the technology is sophisticated, there should be provision for training as well. The technology should be complying with the statutory requirements from time to time. Moreover the technology should not violate the existing norms in the company. All these combined, forms the facilitating conditions in a particular environment.

Hedonic Motivation is the tendency of the individuals to take up actions which give them pleasure and avoid activities inflicting pain (Brown, 2003)

Price Value refers to the Value delivered by the product to the customer. Value delivered should be more than what customer pays to acquire the product. (Dodds and Monroe, 1991)

Habit refers to the automatic actions in response to particular situations either learned or copied externally or formed internally. Embracing a new technology requires, most of the times, to change the existing habits of the customers.

Diffusion of mobile communication in Europe was affected by two factors (1) Market structure (2) Advancement in mobile technology (Gruber and Verboven, 2005). Advancement in technology like transition from analog to digital accelerated adoption and this was found to be the most important factor influencing the adoption of innovation. Competition in the market also enhances the diffusion of innovations as completion decreases the cost of innovation and make the innovation affordable to everyone. Parker and Roller (1997) studied the diffusion of mobile communications in US market from 1984 to 1988 and support the finding by stating that Market structure has an important influence on the adoption. Competition is higher in Duopoly market and prices were found to be lower compared to Monopoly market.

Caselli and Coleman (2001) studied the pattern of computer adoption in OECD countries from 1970 to 1990 and suggest that (1) Education level (2) Openness to manufacturing trade and (3) Overall investment rate in the country affects adoption of innovation. Higher overall investment rate increases the infrastructure/technical capacity to adopt innovation. "Openness" to manufacturing trader enhances the exposure to innovative technologies in other countries/industries.

Availability and advancement of complementary technology/inputs accelerates adoption. Gruber and Verboven (2001) analyzed the diffusion of mobile telephony in Europe during 1990s and concluded that availability and advancement in spectrum capacity enhanced the diffusion. Enhanced spectrum capacity improved quality and quantity of mobile transmission.

Ruyters, Wetzel and Kleijnen (2001) analyzed the adoption of e-Services in Netherlands and concluded that Behavioral Intentions are influenced by (1) Perceived Service Quality and (2) Trust. The antecedent variables affecting these two factors were (1) Organizational reputation (2) Relative advantage (3) Perceived risk. Organizational reputation and Perceived risk are the main variable affecting the Trust factor and all three variables affects Perceived service quality.

Luque (2002) investigated three cases of adoption of sophisticated technologies by US Steel Plants and argues that "Certainty" regarding technology benefits, likelihood of a good resale market for the technology being adopted and lower sunk costs accelerates diffusion. "Sunk costs" are already incurred cost and these costs are often discarded because it cannot be recovered irrespective of the outcome of the decision. "Information Search" cost is a Sunk cost and it cannot be recovered - whether we adopt a technology or not. "Higher Resale Price" is a factor over looked by all other models. 
Teng, Grover and Gutter (2002) compared the diffusion patterns of Email, Fax, PCs and Spread Sheets using Bass model and argued that "Imitative behavior" is the main factor affecting the adoption rate (Internal Influence). The influence of "Innovative Behavior" was found to be very low (External influence).

Lynch and Wood (2002) posits that the "End user involvement" in product development can speed up the diffusion process. End Users should be treated as "partners" for product development. It is an opportunity for the marketers to convince them about the quality, usefulness and user-friendliness of the product. More over end user gets an opportunity to have "Hand on" with the innovation. The end user also spreads positive word of mouth prior in the market prior to market introduction.

Understanding the process of user involvement requires (1) Nature of customer involvement (2) Extent of Customer involvement (Biemans, 1992). Nature of customer involvement is dependent on factors like particular stage of product development, nature or characteristics and number of end user involved. Gruner and Homburg, 2000) Extent of customer involvement depends on (1) Trust (2) Commitment (3) Communication (4) Cooperation (5) Power (Morgan and Hunt, 1994). Trust removes the consequences of power imbalances. The dominant party is always viewed with suspicion by the weaker party. (Pfeffer and Salnick, 1978)

Godinho and Fagerberg (2003) argues that rate of adoption for emerging technologies is directly dependent on organization changes for the adoption of new technology. They posit that Technology innovation is succeeded by Organization innovation. Emerging Technology revolutionizes the way organizations function and incorporates more efficiency in to the system. Organization will have to implement new infrastructure and Train the employees on technology usage. In fact they will have to imbibe - "New Ways of doing things". Innovation activities like $\mathrm{R}$ andD, New Product or Service development and Technology Transfers give impetus to economic growth and social progress. Black and Gregersen (2003) posits that an organization cannot change unless and until the employees in the organization changes themselves. Changing an employee means changing the believes of the employee. Beliefs controls the behavior of individuals. So to initiate change in an organization, the beliefs of the employees should first change. They should perceive change as something beneficial to themselves and to the organization.

Sun, Neslin and Srinivasan (2003) argues that customers are always future oriented in making adoption decisions. Their future expectations about - product price increase/decrease, promotions, product quality/features enhancements affect adoption decisions. If the customer perceives the price to increase in the future - they will stock pile the products to avert the "increased price scenario". During promotion period they buy products in bulk to avail better price/quantity proposition. Customer's perception about the technology advancement in the future encourages them to wait for better results. So future perceptions determines the quantity, quality and occasion of purchase.

Carter and Belanger (2005) studied the adoption of E- Government in USA by analyzing the pattern of usage of citizens at the community event and concludes that (1) Perceived ease of use (2) Compatibility and (3) Trust worthiness are the significant contributors to adoption. The significance of trustworthiness of a system/product was confirmed by the studies of Warkentin, et al. (2002) and Carter and Weerakkody (2008). Tung and Rieck analyzed the survey date from 128 business organizations from Singapore for e-Government adoption and argues that (1) Perceived usefulness (2) External pressure and (3) Social influence are the main adoption contributors.

Today - the market is very competitive, in fact swamped with lot of products. The customers are in a dilemma as to which product they are should chose for a particular 
requirement. Moreover, companies compete against each other by providing information, in fact more than what is required for the customer through various marketing channels. This leaves with totally confused customers and they are prone to making erroneous decisions for their requirements. Here comes the relevance of Lazy User Model (Collan 2007)

Collan (2007) posits that, given a set of solutions/alternatives for a well-defined problem, the customer selects a solution which requires least effort from his side. This theory assumes that the customer is by nature lazy and they always goes for the "least effort solution". This model explains how the customer selects an alternative to his requirement from a set of welldefined solutions. Collan (2007) has developed this model based on their studies in Mobile Phone consumer behavior.

Similar theories of Path of Least resistance or Principle of Least effort (Guillaume Ferrero, 1894) can be found in Physics as well. The theory states that an object or entity naturally takes a path which offers him least resistance or which requires least effort.

In fact there are two factors which affects the solution set taken for consideration. (1) User need (2) User state. User need defines the solution set and User state limits the solution set.

The whole adoption process starts with a "User Need". The "Need" of the user should be a "Clearly stated want" that can be wholly satisfied. The solutions taken for consideration should satisfy the want completely. User state depends on the demographic characteristics of the user and factors - both controllable and non-controllable, in the environment where he operates at the time of solution selection

This model closely resembles Technology acceptance model explained below.

The Effort required can be quantified as a "summation of monetary cost, time invested and physical/mental effort required". Weightage given can vary accordingly to situations.

Collan (2007) has developed this model based on their studies in Mobile Phone consumer behavior. This model can be extended to other sectors as well. Hayes (2009) introduced two more concepts to enrich Lazy user model - by which the applicability of this model can be extended to other fields. (1) Switching cost (2) Peer communication.

Switching cost can be defined as the "cost incurred with changing the supplier/product" (Thomson and Baril, 2009). Switching cost include (1) Financial switching cost (2) Procedural Switching cost (3) Relational Switching Cost (Mahajan, Muller and Srivastava, 2003). Switching cost is a summation of all three components. Switching cost can be a source of competitive advantage for a particular product/brand. Higher the switching cost, more difficult for the customer to change the product/brand.

Hayes (2009) explains the "Effort required" in terms of "Switching cost". Gourville (2006) suggests that the customers always prefer to maintain the status Quo even if the switching cost is nil. The Customer will not change from one alternative to another unless and until that alternative offers them a substantial benefit. The benefit(s)/Value offered should be greater than the switching cost.

The concept of switching cost is very much predominant in Information Technology/Software industry (Shapiro and Varian, 1999). It will be extremely difficult to survive in this sector unless the company knows how to pinpoint, quantify the switching cost and formulate actions plans accordingly.

The second component introduced is Peer communication. Peer communication plays an important role in selection of an alternative. (Makgosa and Mohube, 2007) explains the influence of Reference Group on purchase decisions. For an individual, there always exits some people whose opinions he values while making purchase decisions or while selecting an alternative from the solution set. The customer will be in constant touch with this group. The reference group may consist - your family members, friends or even your co-workers. 
Information elicited from the reference group reduces the customer effort in terms of searching and evaluating the information regarding the product features and user experience with the product. (Bakshy, et al., 2012) establishes the fact, exchange of favorable information in Peer communication, accelerate Peer adoption.

The concept explained in LUM has got many relevant applications while introducing innovative product to the current market or new market especially when the innovation is addition of some new features or improvement of the current features (Incremental Innovation). Concepts like User state, User need, Effort taken by the Customer or Switching cost and Peer communication helps us to formulate effective marketing strategies. User State and User need decides whether the features are relevant to the customer or not. Nowadays the companies give lot of information about their products, which may or may not be relevant to them. In most of the cases, the customer gets confused due to information over load and skips the alternative (Toffler, 1970). Companies should be very careful to impart only the relevant information for decision making through marketing activities. The product should be user friendly, without any hassles for the customer to understand the proper usage of the product, priced reasonably and with benefits relevant to the customer. At times, the campaigns targeting the reference groups of the customers accelerate adoption.

\section{The Lazy User Model}

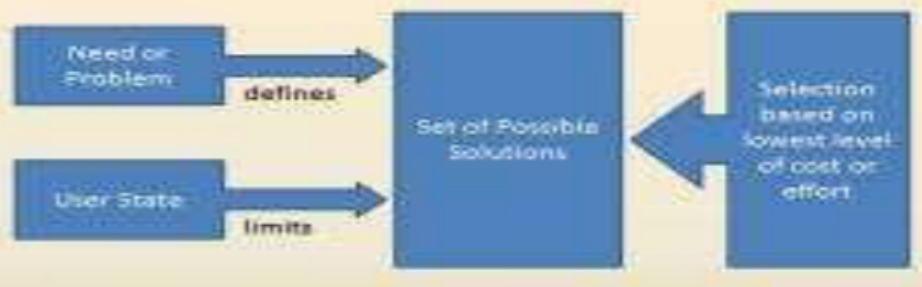

Adapted from Itisard \& Collan, 2009

Figure 15 The Lazy User Model (adapted from Tetard and Collan, 2009)

Aguiar and Reis (2008) took and "Institutional approach" to adoption of e-commerce. The study is based on the findings of Powell and Dimaggio (1991) and stated that various pressures that can have profound influences of adoption are (1) Mimetic pressure - to imitate competitors

(2) Coercive pressure - to imitate the organizations on which they are dependent

(3) Normative pressure - to comply with partners they have a dyadic relationship - shares some information, Rules and Norms. Sharing norms increases consensus and accelerates adoption (Powell and Dimaggio, 1991)

Wang and Liu (2009) studied the usage of Taiwan's Internet Ticketing System by Travelers and posit that web security also affects affective and cognitive attitudes. Affective attitude explains the emotional attachment an individual has towards a product. Cognitive attitude reflects the specific beliefs one has about a particular product. Perceived ease of use has no significant impact on Cognitive and Affective attitude. Perceived usefulness has a positive influence on affective and cognitive components of attitude. Both Affective and cognitive components positively influence behavioral intentions and in turn adoption. The study contradicts the findings of Dong, et al. (2004) which suggests that only cognitive dimension of attitude plays an important role in adoption of Information systems and affective 
components plays a very minor role in adoption. So according to the study done - enhancing perceived usefulness and web security can enhance adoption of innovations.

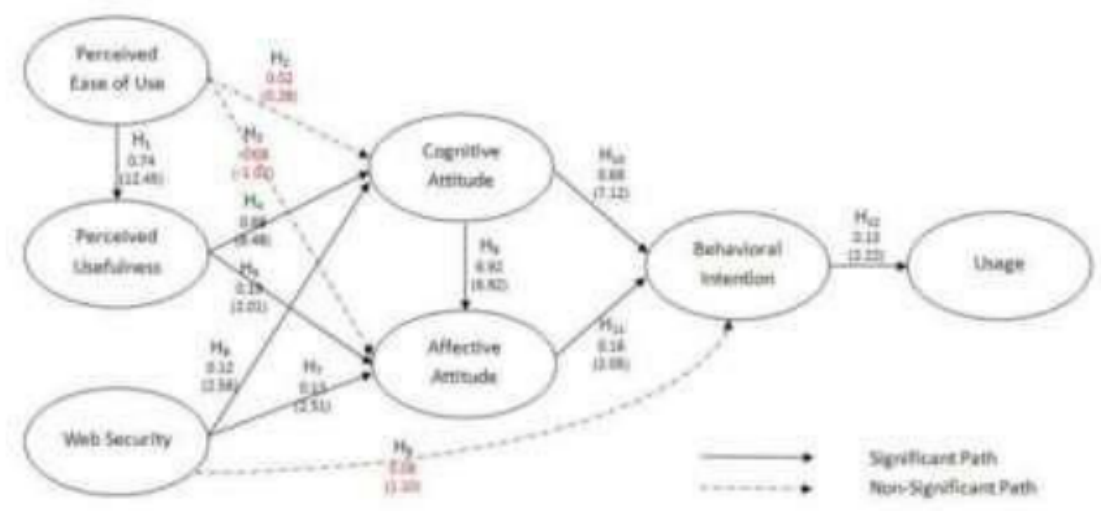

Figure 16 Wang and Liu Model (adapted from Wang and Lie, 2009)

Model of Acceptance with Peer Support describes how the Social ties in the organizations or work settings affect adoption (Sykes, et al., 2009). This is a construct overlooked by other adoption models. This model was based on studies done on the adoption of Information systems in various organizations. Not all employees in an organization are equally competent enough to comprehend the new technology at the same pace. Some are fast learners and some slow learners. So the fast learners should show the "willingness" to help the slow learners and slow learners should show the "Openness" to accept the information from fast learners. This is possible only if social ties in the organization are strong.

There are two types of social ties. (1) First tie is the tie between employees to get help to comprehend the new technology (2) Second tie refers to tie between employees to give help to others to impart information about the new technology. This model names "Give help" and "Get Help" ties as "Network centrality" and "Network density" respectively.

Another two concepts proposed by this models are (1) Valued Network Density - The strength of ties of a focal employee with others in the network and focal employees access to information, knowledge and resources regarding the emerging technology. (2) Value Network Centrality - The perception of peers as to the extent of access a focal employee has to resources and knowledge.

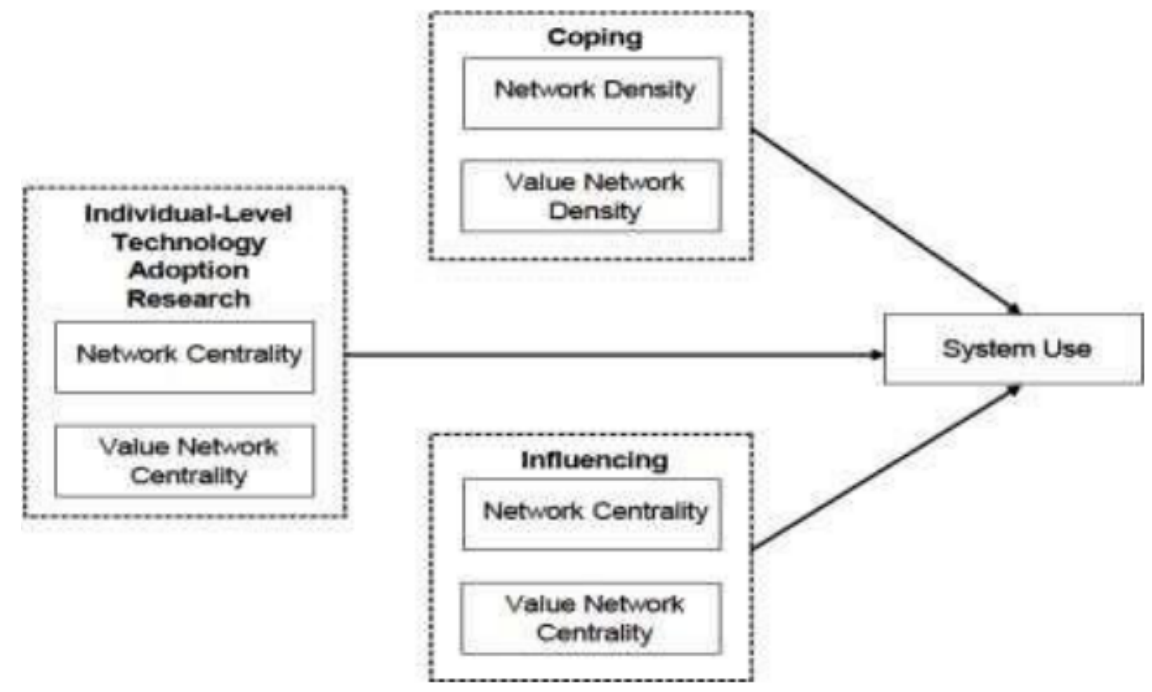

Figure 17 Model of Acceptance with Peer Support (adapted from Skyes et.al, 2009) 
For better deployment of a technology in an organization, this model proposes the importance of "Co-adaptation" of Organization and Technology. The employees in an organization should adapt themselves to the system and the organization prefers the modification, deletion or additions of existing features or new features of the proposed technology based on their actual requirement. It's a two way process. (Barton, 1988).

Co-adaptation occurs following two "Pathways". (1) Coping Pathway - Employees share or gather information and becomes competent to use the new technology (2) Influencing Pathway - Based on the feedback from the employees new technology amends its features or add new features.

Norris and Soloway (2011) investigated about the barriers affecting the adoption of computing technologies in Education sector and concludes the barriers as (1) Lack of vision

(2) Lack of leadership (3) Lack of money (4) Obsolete Curriculum (5) Infrastructure - Both Human and Technology (6) Time taken to change (7) Resistance from Parents (8) Proper Technology assessment.

Porter and Donthu (2006) posits that both technology specific dimensions and personality specific dimensions affects usage of new technology. Technology specific dimensions are (1) Perceived ease of use (2) Perceived usefulness as stated in TAM Model. Personality specific dimensions are (1) Innovativeness and (2) Optimism. Godoe and Johansen (2012) proposes Technology Readiness and Acceptance Model to explain relationship between Personality specific and System specific dimensions. Structural equation modelling was done on data from 186 Norwegian organizations. Innovativeness and Optimism significantly impacts perceived usefulness and perceived ease of use. Perceived usefulness contributes more to the decision to adopt than perceived ease of use.

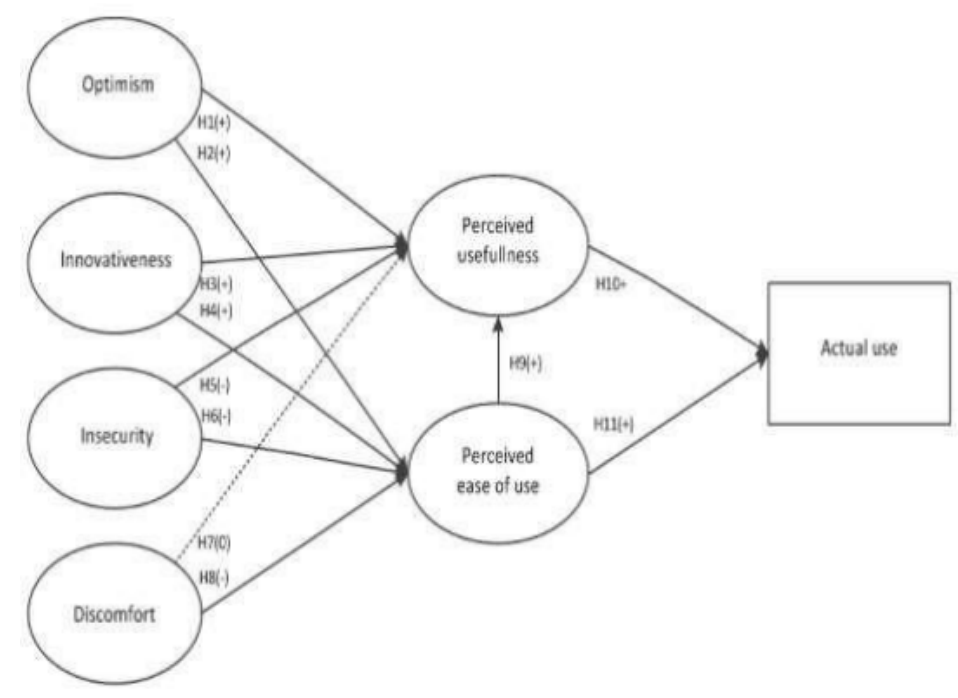

Figure 18 Technology Readiness and Acceptance Model (adapted from Godoe and Johansen, 2012)

Casalo, Flavian and Guinaliv (2012) states that Personal values moderates the influence of antecedent variables. 


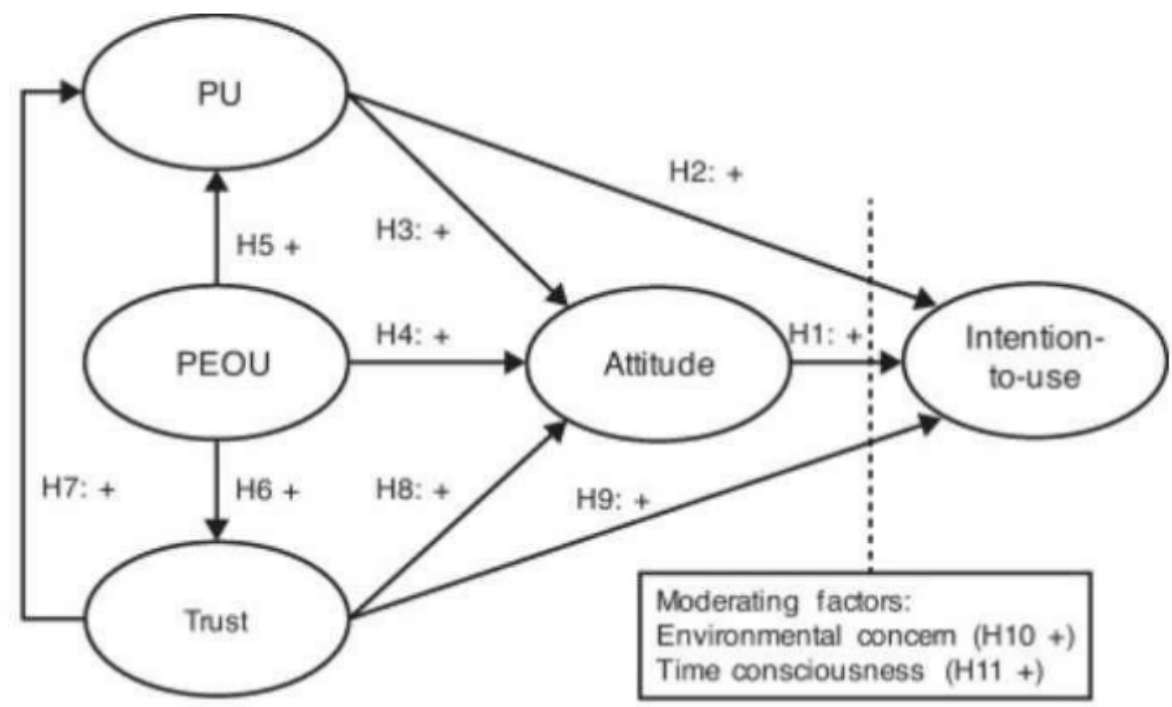

Notes: $P U=$ perceived usefulness, $P E O U=$ perceived ease-of - use

Figure 19 Casalo, Flavian and Guinaliv Model ( as adapted from Casalo, Flavian and Guinaliv, 2012)

Hedonic motivation refers to the tendency of human beings to embrace activities which give them pleasure and to reject or stay away from activities which give them pain. (Higgins, 2006). Customers are always on the search for pleasure and they avoid pain by all means. Customers tend to adopt technology or products which give them pleasurable experiences and rejects products which gives bitter experiences. This is the basis of HMSAM (Lowry and Fienen, 2013). Hedonic Motivation System Adoption model is an extension of Technology acceptance model.

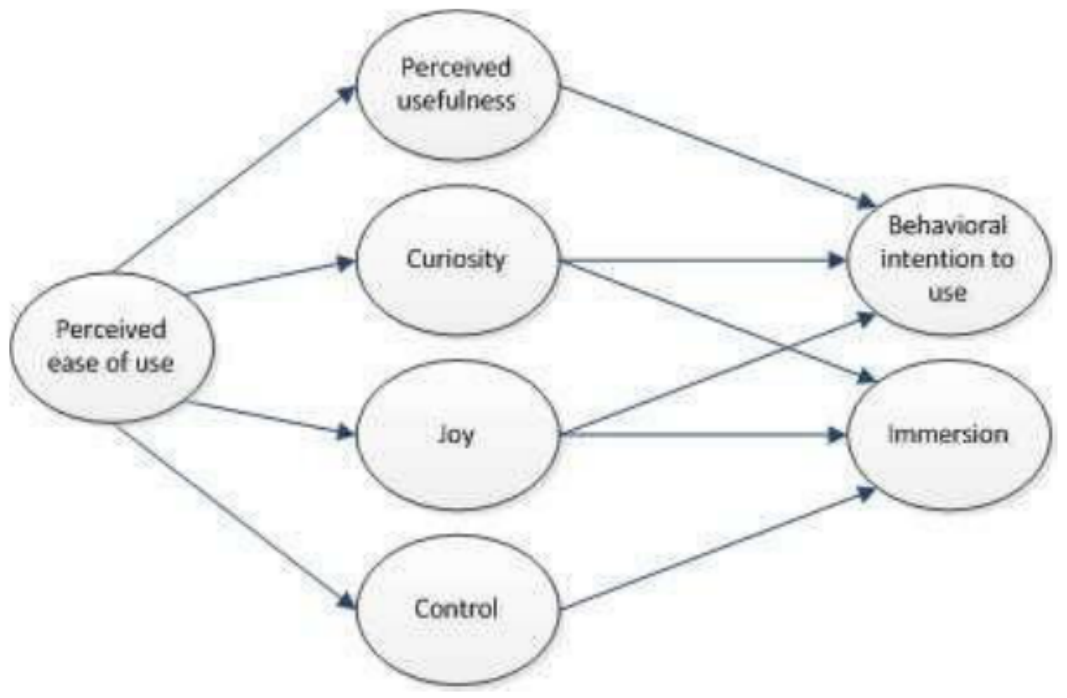

Figure 20 Hedonic Motivation Model (adapted from Lowry et al, 2013)

The company introducing an innovative product should incite a feeling of curiosity in the minds of customers. By providing prototypes to the customers, they should convince the customers about the "User-friendliness" of the product. Usage of the product should give a "Joyful" experience to the customer. The companies should also instill in the minds of customers - that they are competent to use the product. Control refers to the confidence on the part of customer to use the product. Companies should also convince customers about the 
usefulness of the product in customer's context. All these hedonistic factors leads to a favorable buying intention.

Pavlou (2003) studied 155 online customers for adoption of e-commerce and found that (1) Perceived usefulness (2) Perceived ease of use (3) Trust and (4) Perceived risk are the significant factors affecting adoption.

'Boonsiritomachai and Pitchayadejanant (2017) studied the adoption pattern of mobile banking system by "Generation Y" category in Thailand. The main factors identified by them were (1) Performance Expectancy (2) Effort Expectancy (3) Social influence (4) Facilitating conditions (5) Security (6) Self Efficacy (7) Hedonic Motivation. Out of these factors Hedonic motivation was the most import contributor to adoption. Facilitating conditions and Self efficacy have no direct influence on behavioral intention. Security aspect has got a negative influence on Hedonic motivation. Self-efficacy and Hedonic motivation positively influences Behavioral intentions. Hedonic motivation mediates the influences of facilitating conditions and self-efficacy on Behavioral Intensions. Self-Efficacy influences Behavioral Intensions in two ways - (1) Directly on Behavioral intensions and (2) Indirectly through Hedonic Motivation, the indirect effect being stronger than the direct effect.

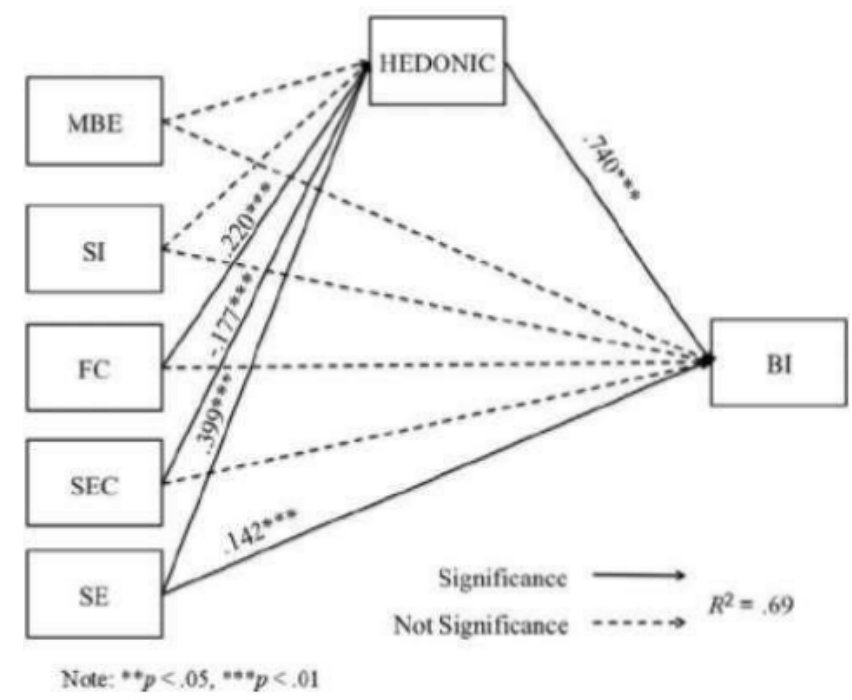

Figure 21 Boonsiritomachai and Pitchayadejanant Model (adapted from Boonsiritomachai and Pitchayadejanant, 2017)

Rangaswamy and Gupta (2000) states that the rate of diffusion can be accelerated if the companies concentrate on effective online marketing strategies. Social media plays an important role in shaping the purchasing intentions of customers now. Word of mouth publicity spreads faster through online channels. This study was based on the applicability of Bass model to internet.

Product reviews plays an important role in adoption of innovation (Clemon, Gao and Hilt, 2006). Product reviews especially online reviews imparts relevant information about product specification and persuades or dissuades customers to buy the products. Product reviews also helps to know the "User experiences" of adopters prior to making purchasing decisions.

A Study in USA establishes the fact that $89 \%$ of customers believes the online product reviews to be genuine. $87 \%$ reported that product reviews results in purchase decisions. (Browne, 2015). Now a days, due to proliferation of social networking site, there are lots of fake product reviews. In fact individuals are hired to "fake reviews", even by reputed manufacturers. 
Lyon and Maxwell (2004) introduced the concept of "Astroturfing" - a method to facilitate fake "Trending" in social websites. Fake profiles are created and the individuals are paid to write favorable reviews. Successful bloggers share strong bond of relationship with thousands of blog visitors. Bloggers can influence visitors to buy the innovative products by recommending these products.

Government Regulation can have a profound influence on the adoption decisions. Baker and Hunter (2001) studied the impact of insurance regulations on adoption of innovative technologies in health sector. A generous health insurance reimbursement scheme encourages patients to go for advanced costly procedures and in turn encourages adoption of innovative technologies. Cutler and McClellan (1996) studied the adoption of angioplasty as a new treat method for heart related diseases and found a positive correlation between favorable government regulations (Generous insurance reimbursements) and adoption of innovation (Angioplasty). Nowadays "Go Green" is the trend everywhere and Environment regulations play an important role in adoption. In certain industries, environmental regulations prohibit or encourage certain technologies (Gray and Shadbegian, 1998). Mowery and Rosenberg (1981) posits that it was safety regulations enforced by Civil Aeronautics Board that accelerated the adoption of innovative technologies in US Aviation Industry. Zhang, et al. (2002) suggests Public concerns and Environmental regulations affecting adoption decisions. Fraj and Martinez (2006) administered questionnaires to 573 individuals selected using SRS to study the factors affecting the usage of innovative products and concluded that (1) Environmental Friendliness (2) Personal values and Individual life styles have profound influences on the choices they make.

Stone model (2002) explains the concepts of "Rank", "Stock" and "Order" effects in adoption of innovation by organizations. The organizations adopt a technology if the utility of it exceeds some critical threshold.(Rank effect).As more and more organizations adopt the innovative technology, the marginal benefits derived from the technology decreases. (Stock effect). When the innovative technology becomes prevalent, the competitive advantages are eliminated and organizations start searching for technologies which gives them edge over their competitors. As the time progresses, due to economies of scale, the technology becomes affordable. The organization adopting the innovative technology for the first time definitely has competitive edge in the market - similar to "First mover advantage". This is "Order effect". But as the number of adopters increases the marginal benefits decreases and a point will come when the organizations will find the innovation "uneconomical".

Frambach and Schillewaert (2002) explains the factors affecting the adoption of innovation in an organization by the employees. One main advantage of this model is that this model takes into account the supplier marketing efforts as well which are not explained by other models (Raechel, Rupert and Garett, 2006). An individual's acceptance of a new technology or system or procedure in an organization depends on supplier strategies, inputs from various social networks and External influences in the work settings. The individual should have a favorable inclination towards the innovation. He should believe that the innovation will enhance his job performance or it will make his task easier. Various characteristics of the individual will have an impact on the adoption process. 


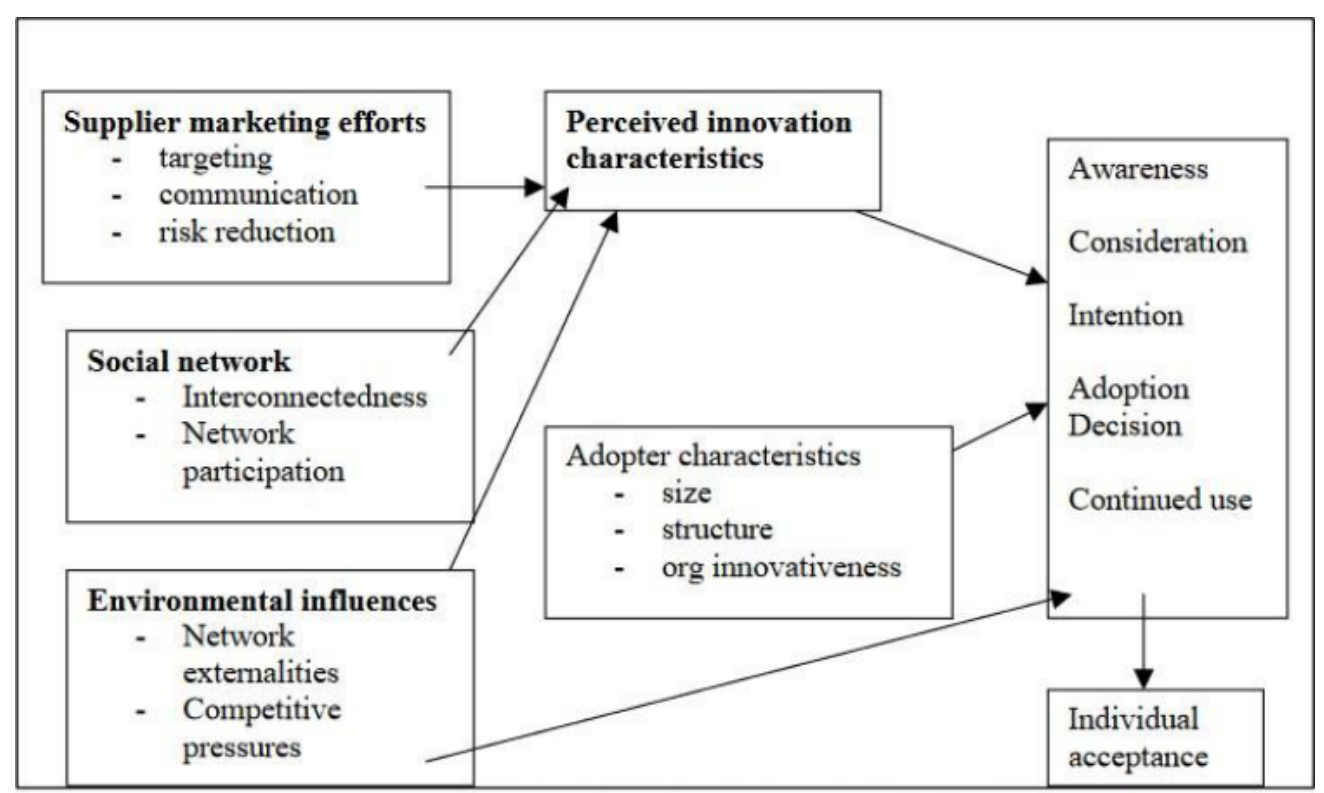

Figure two: Framework of Organisational Innovation Adoption

Source: Frambach and Schillewaert, 2002

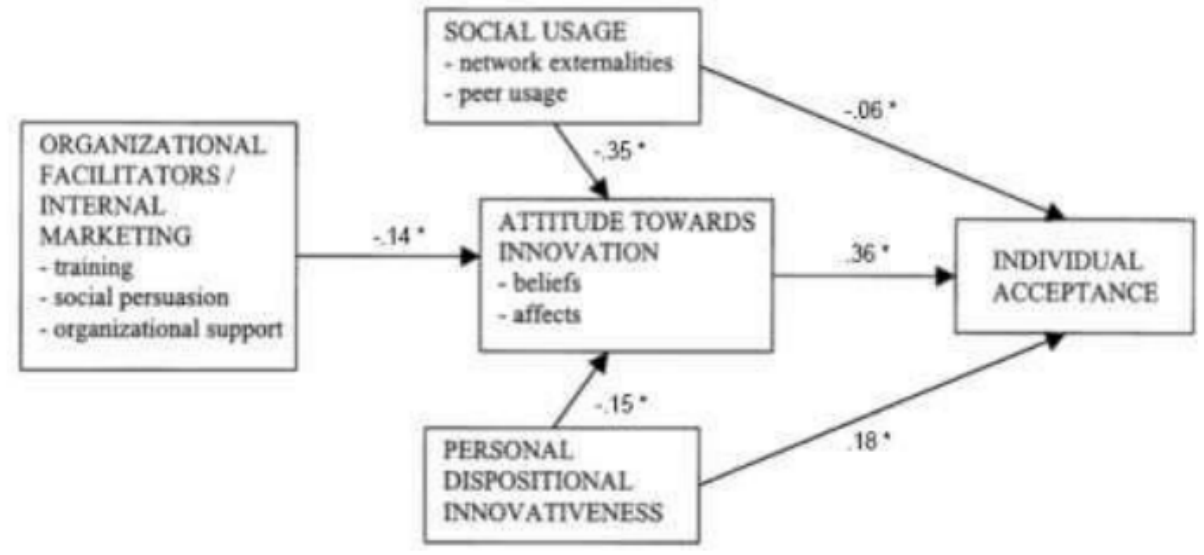

Figure 22 Framback and Schillewaert Model (adapted from Frambach and Schillewaert, 2002)

Armenakis, et al. (2007) suggests that in order to initiate change or adoption of innovation in a organization - five "Change beliefs" are essential. Armenakis, et al. (2007) defines a belief as "an opinion or a conviction about the truth of something that may not be readily obvious or subject to systematic verification". To stimulate the adoption of innovation, the beliefs of individual has to be modified or changed completely. The Change Beliefs proposed by Armenakis, et al. (2007) are (1) Discrepancy - Is there a need to change? (2) Appropriateness - Is this the right choice? (3) Efficacy - Do we have the capacity to change?

(4) Principal support - Can we enlist the support of opinion leaders? (5) Valence - What is the benefit for individual /Organization?

Thomas and Mullaly (2008) states that the adoption of innovation can be enhanced if the organization has clarity regarding the Tangible and Intangible values the innovation can deliver to it. Tangible values are more revenue, lesser costs and increased market share (Values that can be quantified). In Tangible values includes better organizational capabilities, reputation enhancement etc.

Talukder, Haron and Mapunda (2012) studied the adoption of innovation by individuals in an organization and concludes that (1) Perceived usefulness, (2) Managerial support (3) Peers 
(4) Social Influence (5) Demographic factors affects the adoption. The study was based on the data collect by administering questionnaire in an Australian organization.

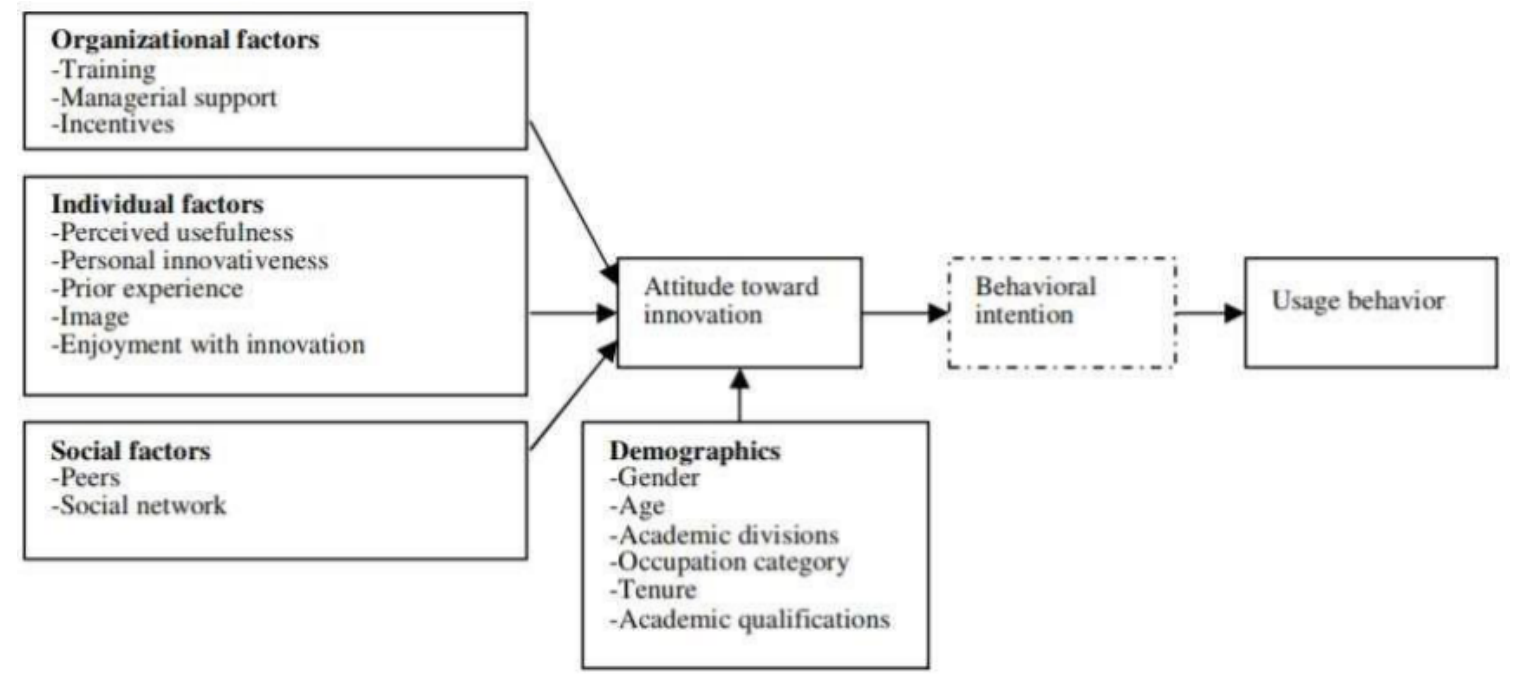

Figure 23 Majharun Talukder Model (adapted from Majharun Talukder, 2012)

Arnholt and Batte (2003) studied six farm in Ohio and posits that (1) Profitability (2) Onfarm research and (3) Quality information provided by PA for decision making are the main concerns to be addressed to accelerate adoption of innovation. Hudson and Hite (2003) posits that the adoption of innovation is influenced by the adopters willingness to pay and this increases with education level and perceived benefits.

High entry cost, High risk and Farmers Income were the main drivers/inhibitors for the adoption of innovative technologies among farmers (Diederen, Meijl and Wolters, 2003). Watcharaanantapong, Lambert and Roberts (2014) suggest income to have a positive correlation and age to have a negative correlation with adoption of innovation.

Higher the environmental benefits delivered by innovation, higher will be the adoption. Silva, Lira and Pereira (2011) studied adoption of innovation among sugar cane farmers and supports this view as environmental benefits is the most important factor along with better yield and profitability expectations. The non-adoption of technology can be attributed to unfamiliarity, irrelevant application and high costs. (Gillespie, Kim and Pandel, 2007).

Reichardt and Jürgens (2009) also attribute cost as the main hindrance for adopting innovative technologies in agriculture. The study also considers (1) lack of technical support and (2) lacks of skills to interpret data as the main barriers for adoption. Gelb and Voet (2009) studied the adoption of ICT among farmers and put across important variables of adoption as (1) age (2) education (3) farm size (4) type of production (5) income (6) software features (7) ease of use and (8) Perceived benefits (9) Training

Paudel, Pandit, Mishra and Segarra, 2011. Analysis of data among cotton farmers in UA for adoption of PA technology concluded that the factors affecting the adoptions decisions are (1) Cost (2) Time constraints (3) Satisfaction with the current practice (4) Formal education and (5) Farm size

Aubert, et al. (2012) studied adoption of innovation among farmers and enriched the TAM model by adding other variables like compatibility, employer's knowledge, information, operators' knowledge, operative innovativeness, perceived resources, quality of external support, relative advantage, trialability, voluntariness. Tey and Brindal (2012) identified SocioEconomic, agricultural and environmental, institutional, behavioral, informational and technological factors affecting adoption of innovation in agriculture. 
Antoni, et al. (2012) studied the adoption of GPS guidance among cotton producers and found out that (1) Input cost savings and (2) Age are the important factors affecting adoption. Velandia et al, (2013) found this relationship to be valid for Small cotton producers.

Pierpaolia, et al. (2013) examined the drivers for adoption of Precision Agriculture tools and suggested the factors as (1) Farm size (2) Cost reduction/Higher revenue (3) Total income (4) Land Tenure (5) Farmer's education (6) Computer Familiarity and (7) Access to information. The most important aspect influencing adoption was Firm size followed by Computer familiarity.

Nkegbe and Shankar (2014) studied the adoption of Soil and Water conservation practices in Ghana and proposed (1) Access to information, (2) Social capital (3) Per capita land holding and (4) Wealth as the important drivers of adoption.

Tohidyan and Moghaddam (2015) analyzed the attitude of Farmers and Agriculture consultants in Iran towards PA. The theoretical underpinning taken for this study was TAM Model. Behavioral Intentions decide whether the individual will adopt the innovation. The most important variable affecting behavioral intention is Behavioral attitude. A favorable attitude towards innovation accelerates the adoption. Seminars/Workshops can be conducted to elicit a favorable response towards the innovation. The most important variable affecting behavioral attitude is usefulness of technology. Confidence to master and use the technology also affects Behavioral attitude. Trainings are very vital to impart the usefulness and confidence to farmers. Adoption of innovation are also affected by two more variable (1) Perceived ease of use and (2) Individual innovativeness. The technology should be simple/user friendly. Individuals with high "Innovativeness" have high propensity to adopt innovative technologies.

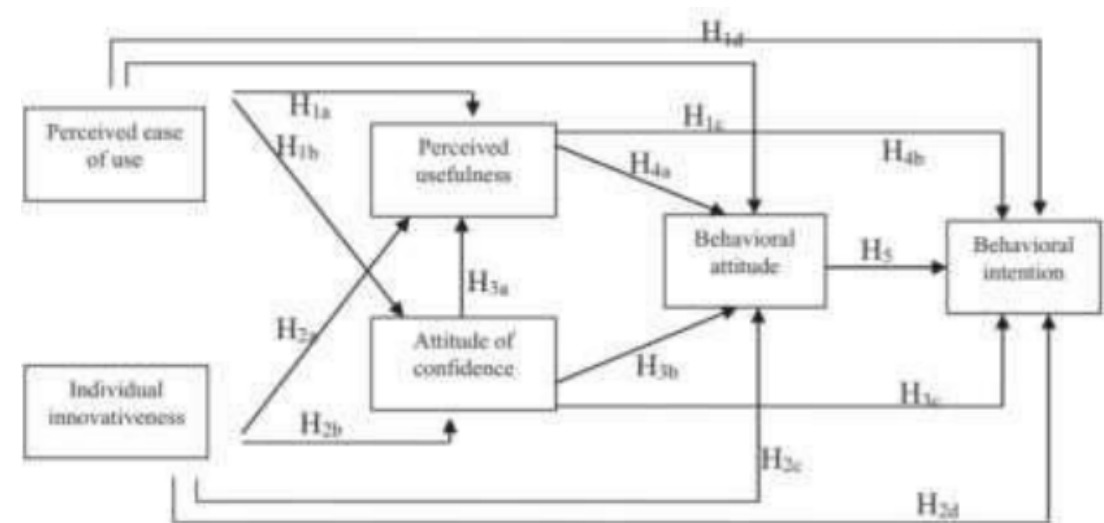

Figure 24 Tohidyan and Moghaddam Model (adapted from Tohidyan and Moghaddam, 2015)

Reducing Environmental impact and increasing the income are the main drivers for adoption of innovation among farmers. (Dillon, Warner and Obrecht, 2017)

Pignatti, Carli and Canavari (2015) conducted studies in adoption of innovation in agriculture in three countries - Iran, Greece and Turkey. Through Focus group and indepth interviews they concluded that social-demographic features like age and education level affects adoption of innovations. Young, highly educated farmers favored adoption of innovation than older less educated farmers. Farmers attitude - fear of technology, Back ground of the farmers and previous experiences can also affect adoption. Farmers knowledge and skill set can also play a significant role in adoption. Fear of technology and lack of knowledge /skill set can be done away with Training and Quality Tech Support. Experience/information sharing by the adopters can have a significant impact on prospective adopters. Farm characteristics like land ownership, firm structure and organization, farm size, 
land size and innovation cost/affordability also affects innovation. Famers having membership in organizations have better access to information about innovative technologies/trails and demos. The innovation should be small in size, easy to use, compatible and it should not create drastic organizational changes. It should not disrupt the current operations. The innovation should deliver observable and understandable outputs and concrete benefits. To accelerate innovation, the innovator can collaborate with the farmers in the development stage of innovation. Getting the innovation tested and certified by the authorized bodies can speed up adoption. Market pressure, Government policies and availability of public funding can influence adoption decisions.

Figure 1. Adoption process stages and relevant factors (in-depth interviews)

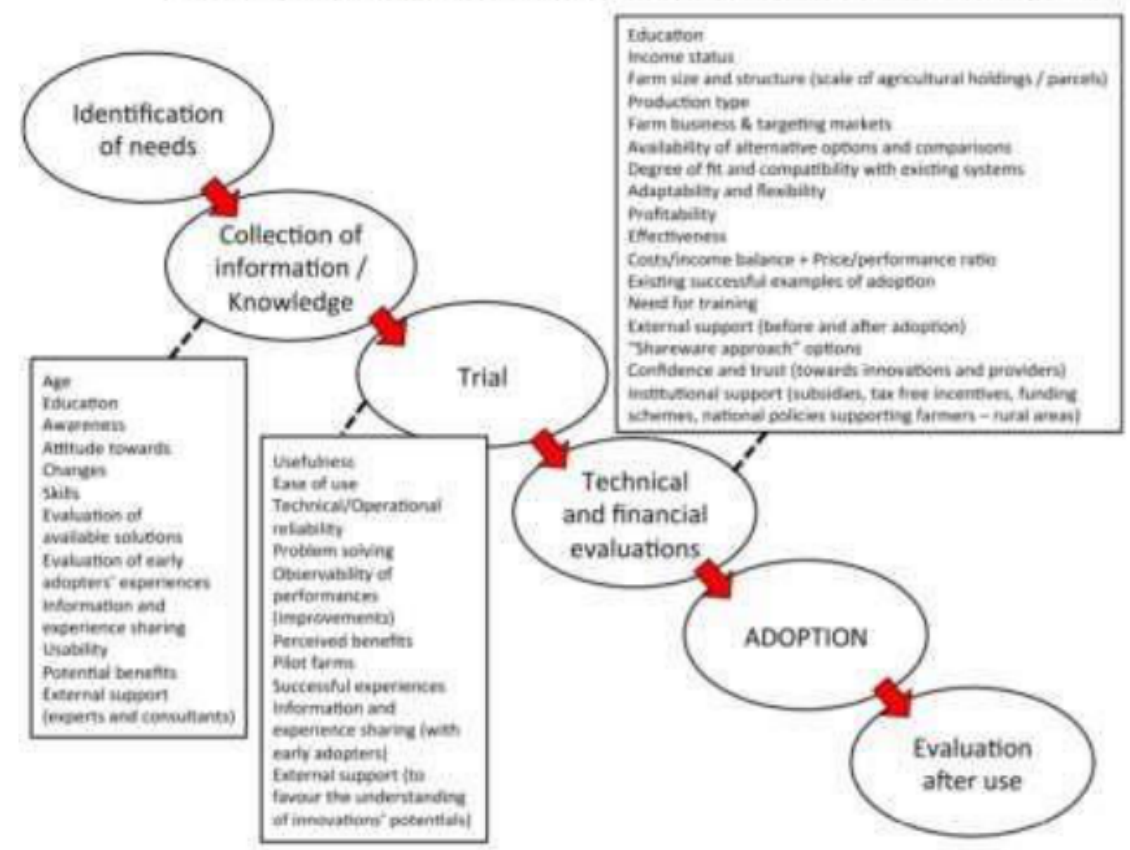

Figure 2. Adoption process stages and relevant factors (focus groups)

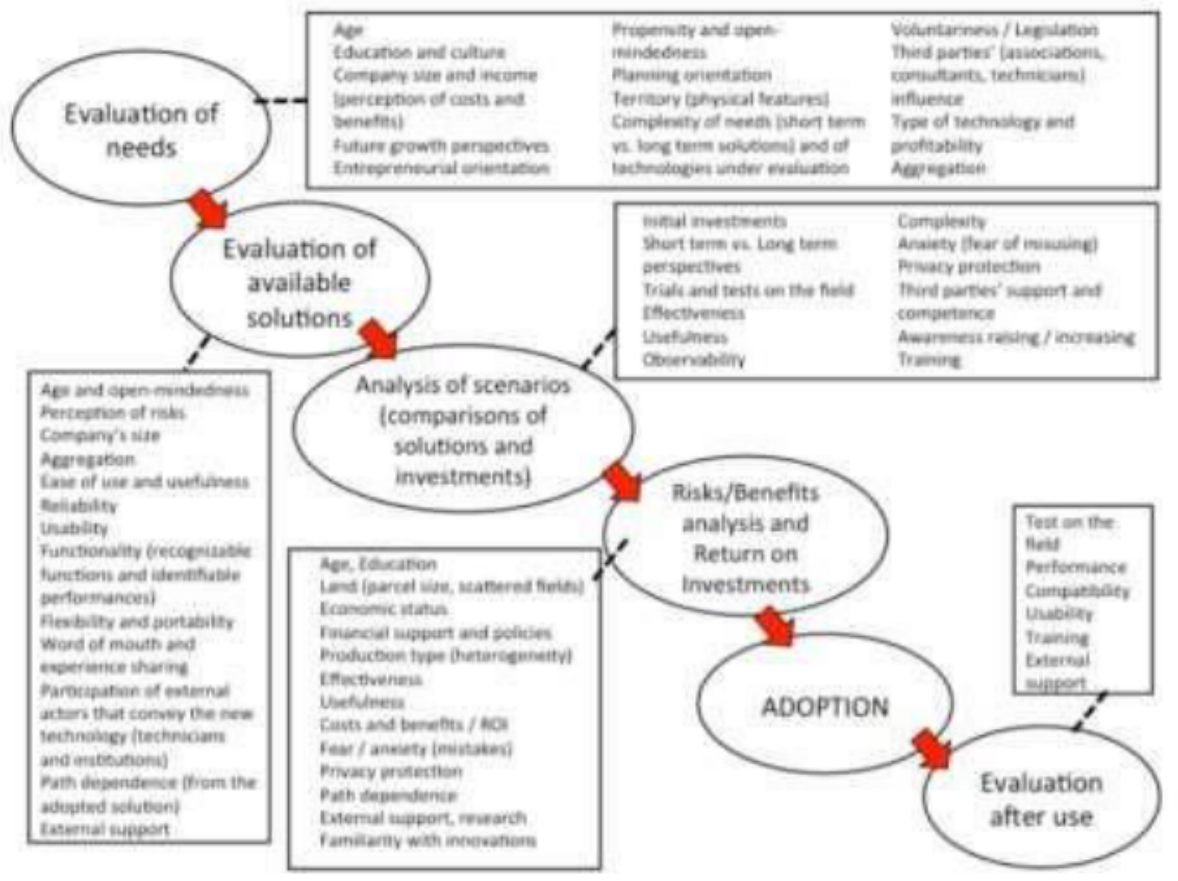

Figure 25 Pignatti, Carli and Canavari Model (adapted from Pignatti, Carli and Canavari, 2015) 
Difficulty to master the innovative technology is cited as the main barrier for adoption of PA technologies in agriculture. (Borhi, et al., 2016). Castle, Lubben and Luck (2016) analyzed the farmers in Nebraska and suggested that (1) Tech Savyness and (2) Large fam size had a positive correlation with innovation adoption whereas age and gross farm income do not affect adoption.

Guseo and Mortarino (2015) studied the diffusion of Innovative drugs in Pharmaceutical sector and argued that the diffusion of knowledge about the drugs is an important factor affecting the diffusion of drugs in the market. The pharmaceutical market is a scenario where alternative drugs compete fiercely to capture the market share. The adoption of a particular drug depends on the awareness about the drug to the doctors. Competitors try to enhance the "Awareness levels" of doctors through smart medical representatives or by conducting seminars. These activities create a significant impact on the awareness levels and in turn the adoption rates. "High awareness levels" in the market accelerates diffusion. Prospects at any time is proportional to the size of awareness group

Perez, Popadick and Cesar (2017) investigated the internal factors affecting the adoption of Electronic Health Record System (EHS) namely (1) Decision types (2) Communications

(3) Nature of social systems (4) Promoters of change. He conducted a Structural Equation Modelling using SMART PLS on th data collecting using questionnaire from Technicians, administrators, Nurses and Doctors and posits that Promoters of change had no significant impact on adoption. Decision types - if it is "Authoritarian" decisions - it speeds up adoption, whereas collection decisions slow down adoption. More the number of people involve in the process slower will be the decision and subsequent adoption. Communication channels can be either Face to face (One to one) or Mass - has got a significant impact on adoption. Nature of social system - like presence of standards or visionary leadership accelerate the adoption process.

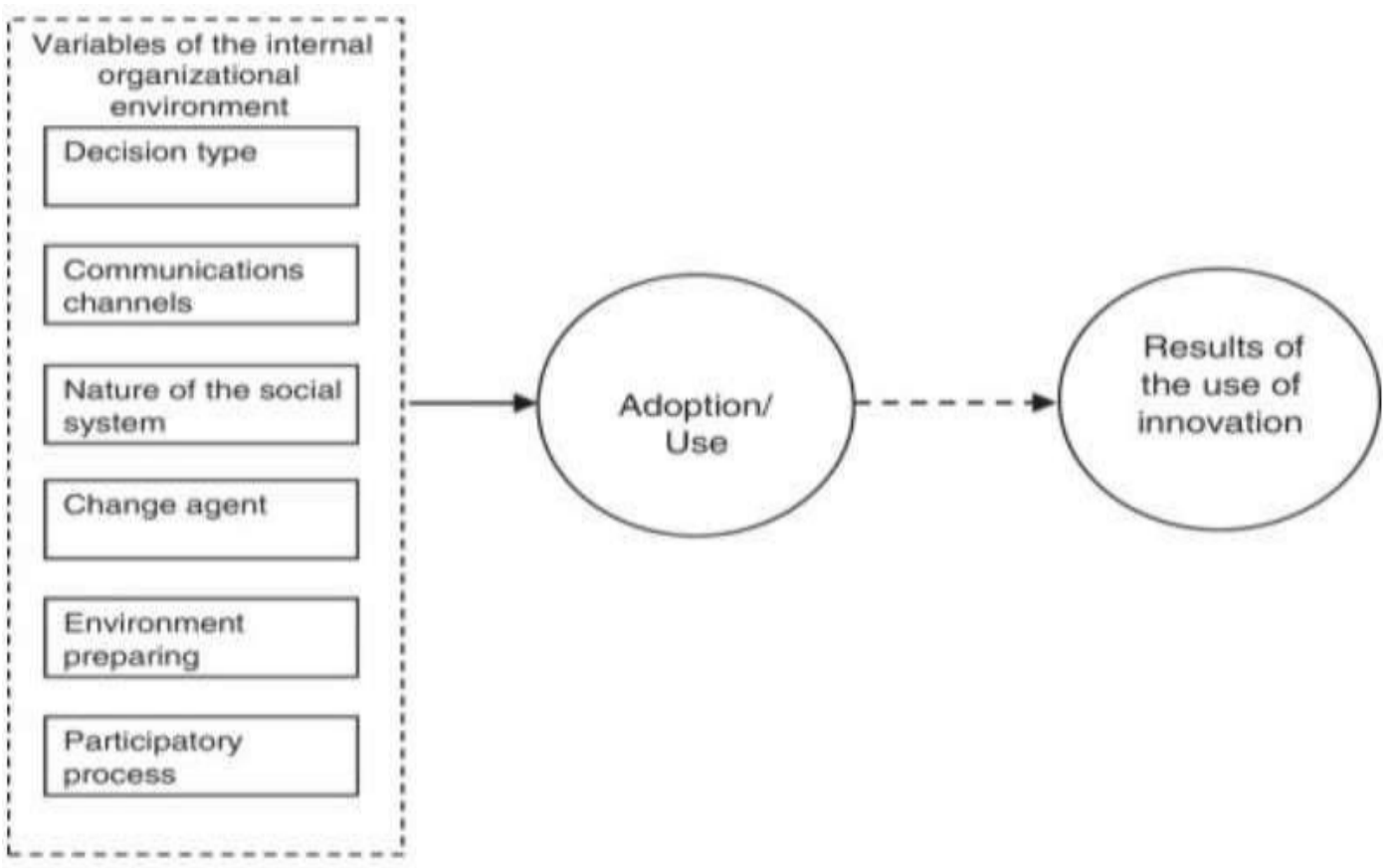

Figure 26 Perez, Popadick and Cesar Model (adapted from Perez, Popadick and Cesar, 2017)

EMRAM Model (HIMSS Analytics, 2018) helps to measure and accelerate the adoption of EMS functions in the hospitals - to replace "paper based systems" and give better service to patients. It's an eight step model (0 to 7) which helps us to assess where "a hospital stands" in terms of technology adoption compared to its competitors in the health sector. 


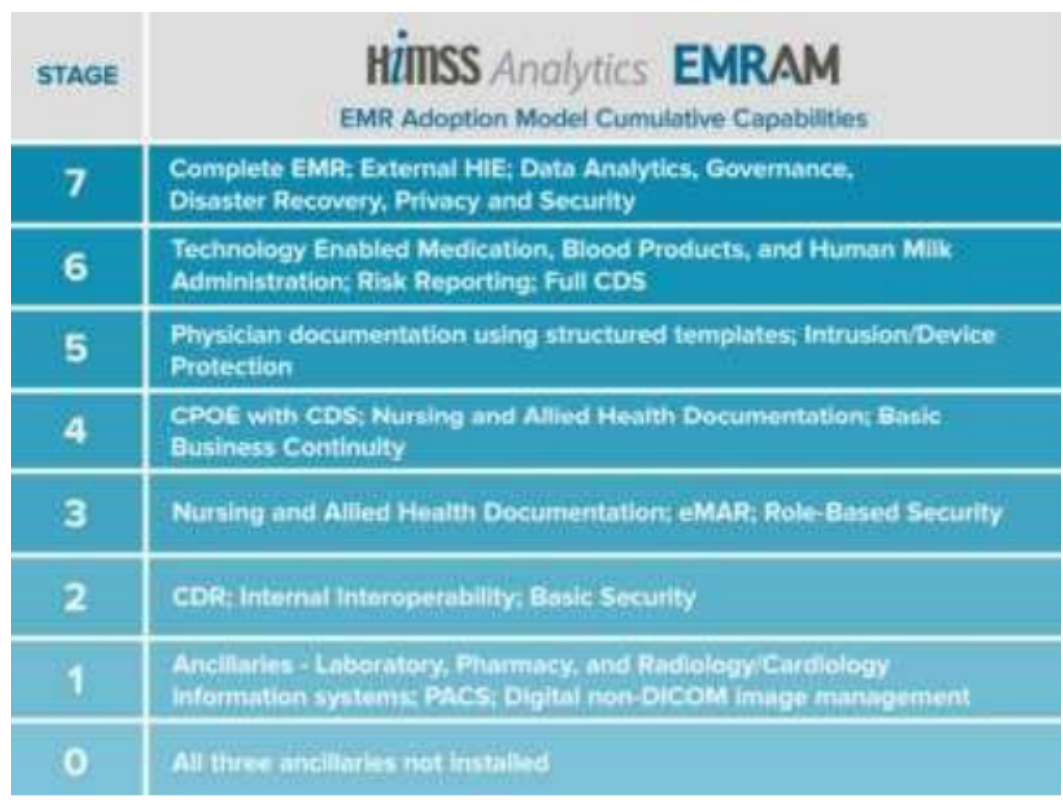

Figure 27 EMRAM Model (adapted from HIMSS Analytics, 2018)

EMRAM model help us to (1) "Asses" the current level of adoption (2) "Chart" current level of adoption and accomplishments (3) "Compare" with other hospitals "(4) "Implement" with is required to achieve the desired level of adoption based on bench marks in the healthcare industry.

Developing an industry specific model taking in to consideration the hard realities of the industry helps the adopters to asses and evaluate "where" the organization stands right now and "where" it should reach to remain competitive based on industry bench marks.

Health Catalyst (2018) proposes a model to enhance the adoption of health care analytics in hospitals. This models helps to analyze the analytics capabilities required for a hospital, sequence of steps to be followed for the complete implementation, the resources at disposal for the evaluation and implementation of various Health Analytics packages available in the market. Proper implementation of the basic modules is required to enhance the capabilities of the Analytics packages by incorporating advanced features in the future. This is an extension of EMRAM model

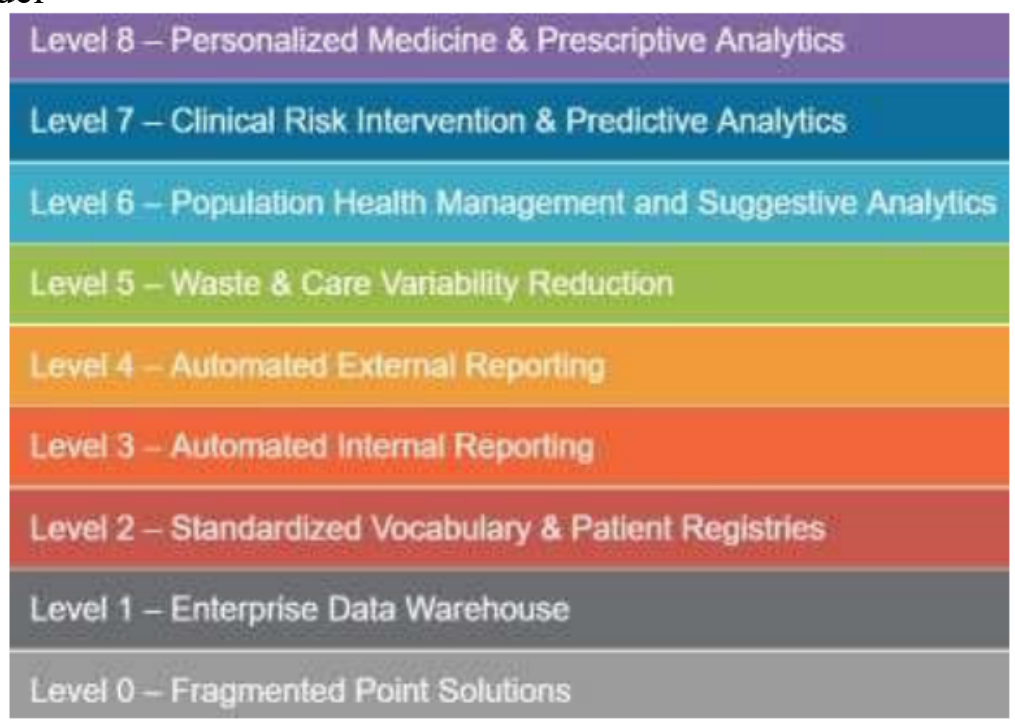

Figure 28 Health Catalyst Model (adapted from Health Catalyst, 2018) 
Mengesha and Garfield (2018) studied the adoption of telemedicine in Ethiopian health care sector by surveying 205 medical professionals and argues that the factors affecting adoption are (1) Facilitating conditions (2) Compatibility with medical practice (3) Compatibility with preferred working styles. Facilitating conditions contributes the most to adoption of Telemedicine. The main barrier for technology transfer from "developed" to "less developed" countries is "facilitating conditions.

Harvey (2009) studied the diffusion of innovative services and proposes that factors (1) Quality of results, (2) Quality of Process (3) line of visibility (4) conformity with industry standards (5) Brand Value (6) Word of mouth (7) Referral value (8) Cross buying and up buying (9) Number of brand loyal customers and (10) Multiple channels affects the adoption of innovation. Customer satisfaction leads to favorable Word of mouth which in turn leads to adoption or rejection of products. (Wagenheim and Bayon, 2007). Wagenheim and Bayon's study (2007) helps to understand the market interactions. Dissatisfied customers spreads bad word of mouth and hinders diffusion of innovation.

Customer satisfaction can be measured in terms of positive customer experiences (Millard, 2006). A satisfied customer recommends the innovation to others.

Mathematically,

$$
\ln \left(X_{t}-X_{t-1}\right)=b+c_{1} t+c_{2} \ln \left(X_{t-1}\right) .
$$

Where $\mathrm{X}(\mathrm{t})=$ Proportion of adopters at time " $\mathrm{t}$ " and $\mathrm{b}, \mathrm{c} 1, \mathrm{c} 2=$ Constants

Bredillet, Yatim and Ruiz (2010) studied the adoption of "Project Management" in organizations and concluded that the most important barrier to overcome to stimulate adoption was the "cultural change" required. Organizations/Individual were very hesistant to change the "Current Way of doing thing" even when the change was for better results.

Findings of Oster and Thornton (2010) support the findings of Ellison and Fudenberg (1995). Oster and Thornton studied the adoption of menstrual cup in Nepal and conclude that "Peer exposure" enhances the adoption of innovation as the "prospect adopter" learns about the innovation and its usage from peers.

DeVries (2014) posits that the adoption in public sector is affected by (1) availability of resources (2) leadership styles (3) Risk aversion (4) Clarity of goals (5) Conflicts (3) Organizational structure. Gabris, Golemblewski and Ihrke (2001) states that better "credibility" of the administrators fosters a better relationship between administrators and the company board and this relationship encourages adoption of innovation.

Kekana, Aigbavboa and Thwala (2014) studied the adoption of Building Information Modelling (BIM) in South African Market and proposed that the main factors influencing the adoption are (1) Contractual Issues like Licensing and Insurance (2) Personal Inadequacies in terms of education and skill set.

Pyzalska (2018) studied the factors affecting the adoption of "Innovative Energy Services" in the energy market and argues that the first and foremost factor affecting adoption is the relevant and reliable information to incite interest and to reduce the perceived risk. Distribution channels can also play a significant role in adoption. Financial and Non-financial benefits and cooperation between "policy makers, energy suppliers and power system operators" can also accelerate the adoption.

Integrated Acceptance and Sustainability Assessment Model helps to analyze the Pre and Post adoption behaviors (Aizstruata, Ginters and Eroles, 2015). Most of the diffusion models explains the process till adoption. Diffusion models has overlooked two important concepts which will lead to post satisfaction and good word of mouth, (1) Total acceptance of the Technology by the organization or the customer (2) Sustainability of the Technology Accepted Technology should function smoothly in the long run. (Aizstruata, Ginters and 
Eroles, 2015). The technology should cater to the requirement of all stake holders in an organization to their utmost satisfaction and the technology should sustain it performance without major glitches in the long run.

IASAM helps to predict the acceptance and sustainability of existing and emerging technologies. IASAM has borrowed five attributes along which the Technology will be tested from Rogers Diffusion Theroy (1962) (1) Relative advantage, (2) Compatibility, (3) Complexity, (4) Trialability, (5) Observability. IASAM2 - a revised model introduces the concept of a sixth attribute - Feedback for evaluating technology.

IASAM2 further categorized the factors affecting the acceptance and sustainability of Technology in to four. (1) Management - Successful management of all assets in an organization (2) Quality of Technology (3) Acceptance and Economical benefits (4) Domain development - How it affects the society/industry as a whole. IASAM helps to identify the factors that should be complied with for technological sustainability. Feedback from the existing users helps for the betterment of technology.

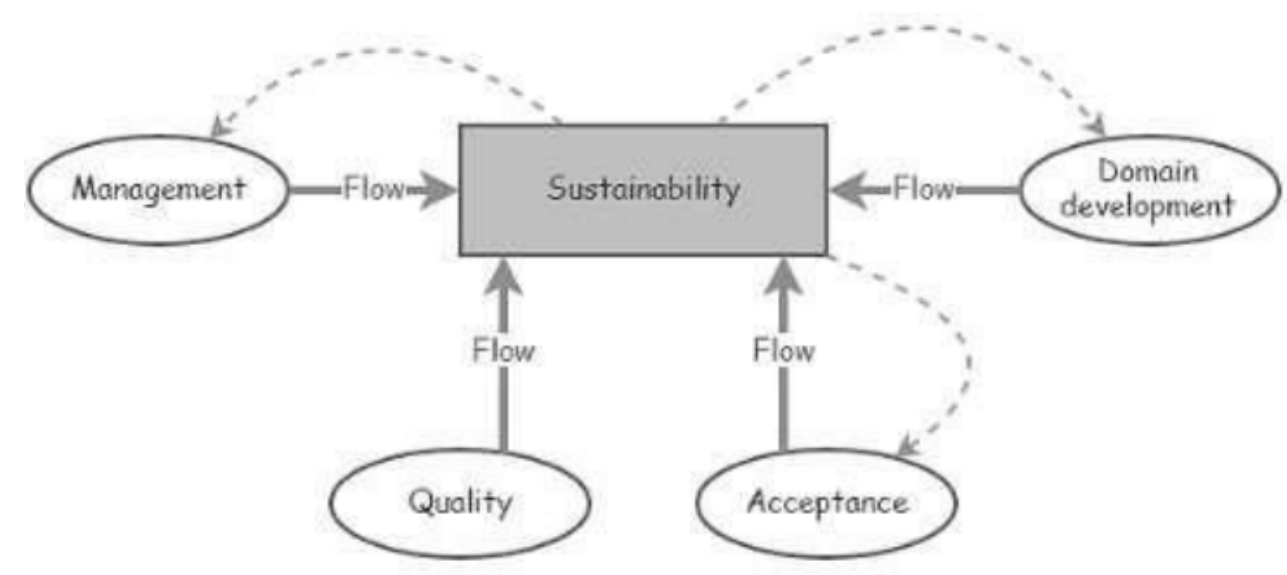

Figure 29 Integrated Acceptance and Sustainability Assessment Model (adapted from Aizstruata, Ginters and Eroles, 2015)

\section{CONCLUSION}

The market can be divided in to various categories based on Perceived expectations. Each cluster exerts influence on other clusters through different channels. This classification helps innovators to pinpoint pockets of innovations, to convince these pockets and subsequently to create a cascading/bandwagon effects to other clusters. The whole idea is to capture niche markets and then to grow from there. (Stauffer, Dietrich and Aharony, 1994). The process of Customer Road Mapping helps innovators to identify the key needs or preferences (Sandia, 2004). Future expectation about price decrease or features addition prolongs the adoption. The timing between incremental innovations should not be too long. If it is too long, the product itself fades to oblivion or the adopter gets bored with the technology itself (Lehman and Weinberg, 2000). Adopter expects the innovation to give the desired results within the time budgets. Exceeding the time budgets leads to dissatisfaction and ultimately abandonment of innovation (Dust and Kwan, 2005).

The concept of innovation adoption should be viewed from an "Organizational/Individual" change perspective. This perspective helps to reduce the resistance to change or inertia to continue with the same age old technologies or systems (Stone, 2002). Adopters prefer to use those technologies which enhance the pleasure and reduce effort/suffering. This concept is called Hedonic motivation. So the innovator has to design innovative products in such a way that the usage of the product should deliver a 
pleasant experience to the end user (Higgins, 2006). Brand loyalty affects adoption positively. The adopters give due consideration to the reputation of the innovator in the market (Kaine, 2004). End User involvement in the development of innovation makes the art of convincing much easier (Lynch, 2002). The web security/encroachment to privacy is an important concern for adoption of e-services.

Optimism and Innovativeness are the accelerators of adoption. Discomfort and Insecurity are the inhibitors of adoption (Parasuraman, 2000). Product Reviews in various social networks/blogs casts positive/negative influence on the adoption decisions (Nassar, 2014). High Resale value of technologies/Exchange or Trade in offers speeds up adoption. There are some costs incurred in the adoption process which cannot be recovered. Information Search cost is the Sunk cost which cannot be recovered (Luque, 2002).

The innovative products are divided broadly into two categories: (1) Brown Goods: Possession of which enhances the status levels. There are no substitutes for these products and diffuses faster. (2) White goods: Regularly used with many alternatives and takes time to diffuse (Tellis, 2002). Total acceptance and sustaining an innovation in an organization depends of the regular feedbacks and subsequent actions taken for improvements (Statnikova, 2005). The process of diffusion is affected by performance for early adopters, fashion for middle adopters and legitimacy for late adopters (Wang, 2010). The strength of social ties in an organization facilitates the flow of information and faster decision making (Sykes et al, 2009). An innovation sustains itself if it crosses the minimum requirement of adopters in a market. This threshold point or tipping point is called Critical Mass (Gladwell, 2000).

Categorization of adopter sets are done by various scholars as (1) Influencers and Imitators (Butle and Joshi, 2007) (2) Technology Enthusiasts, Visionaries, Pragmatists, Conservatives, Skeptics (Wiefel, 2002) (3) Erasers, Ferrules, Wood, Sharp ones and Leaders (McKeown, 2012)

The Factors from various studies are consolidated as follows:
1. Centralized Decision Making
2. Network Externalities
3. Opinion Leadership/Technology Stewards/Leadership
4. Timing of Innovation/Innovation Policy
5. Consumer/Organizational/Product Category Innovativeness
6. Relative advantage/benefits/Perceived usefulness
7. Ease of use/Effort
8. Work Experience/Education Level/Training
9. Subjective Norms/Personal Traits
10. Image/Reputation/Trust/Credibility
11. Job Relevance
12. Result Demonstrability/Output quality
13. Price
14. Market Structure
15. Technology advancements/Complimentary Technology/Infrastructure
16. Fashion/Seasonality
17. Resale Price
18. Imitation/Substitution
19. Environmental Friendliness/Standards/Govt. Regulations
20. End User Involvement
21. Information Access
22. Hedonic Motivation
23. Inertia/Satisfaction with existing technology
24. Self-Efficacy 
25. Management support/Organizational Change

26. Supplier Marketing Efforts

27. Organizational Size/Culture

28. Internal Marketing/Peer communication/Word of Mouth/Advertising

29. Compatibility/Customization

30. Time Budget

31. Availability of alternatives/Switching cost

32. Income/Purchasing power

33. Distribution channel

34. Trialability

35. Web Security

The factors affecting adoption can be categorized as (1) Organizational, User, Project, and Technological (Statnikova, 2005) (2) Contextual factors and Personal Factors (Botha and Atkins, 2005)

Diffusion researchers combined process stream and factors stream of research post 2000. The process of diffusion cannot be explained without combining these two streams. Many studies focused on Organizational adoptions. Studies combined organizational and individual perspectives of adoption to frame an holistic view of adoption process. In practical sense, to remain competitive, the organization has to adopt the innovation and the individual has to put this innovation in to use in their daily operations. Very few studies focused on Pre - Adoption factors which is very vital to facilitate smooth adoption. Similar is the case with Post adoption behaviors. Most of the studies dealt with factors affecting the implementation of innovation.

\section{REFERENCES}

[1] Ahsanuzzaman, A., 2015. Duration Analysis of Technology Adoption in Bangladesh. In: 2015 AAEA and WAEA Joint Annual Meeting, San Francisco, 26-28 July 2015. San Francisco: Agriculture and Applied Economic Association.

[2] Aizstrauta, D. and Ginters, E. and Eroles, M.P., 2015. Applying Theory of Diffusion of Innovation to Evaluate Technology acceptance and Sustainability. Procedia Computer Science, 43, pp. 69-77.

[3] Andersen, A., 1996. Economic Impacts of Casino gambling in the United States: Macro Study. US: American Gaming.

[4] Antonelli, F., 1993. Backward-Forward Stochastic Differential Equation, Annals of Applied Physics, 3(3), pp. 105-132.

[5] Aquiar, A.S. and Reis, A.P., 2008. Why do firms adopt e-procurement systems? IEEE Transaction in Engineering Management, 55(1), pp. 120-133.

[6] Armenakis, A.A. and Berneth, J.B., Pitts, J.P. and Walker, H.J., 2007. Organizational change recipients scale. Development of an assessment instrument. Journal of Applied Behavioral Science, 43(4), pp. 481-505.

[7] Armstrong, G.M. and Feldman, L.P., 1975. Identifying Buyers of a Major Automotive Innovation. Journal of Marketing, 39(1), pp. 47-53.

[8] Arnholt, M.W. and Batte, M.T., 2003. Precison farming adoption and use in ohio: Case studies of six leading adopters. Computers and Electronics in Agriculture, 38(2), pp. 125139.

[9] Assael, H., 1998. Consumer Behavior and Marketing Action. Cincinnati, OH: South Western Publishing.

[10] Aubert, B.A., Iriyama, A., Kay, O. and Kishore, R., 2012. Investing the relationship between outsourcing and innovation. Information System Outsourcing, 9, pp. 23-36.

[11] Baker, D. and Hunter, R., 2002. Guide book to Decision Making Methods. USA: Department of Energy. 
[12] Bakshy, E., Rosenn, I., Marlow, C. and Adamic, L., 2012. The role of social network in information diffusion. In: Proceedings of 21st international conference on WWW. Lyon, France. 16-20 April 2012. France: ACM

[13] Baptista, R., 2000. Do Innovation diffuse faster with in geographical clusters? International Journal of Industrial Organizations, 18, pp. 515-535.

[14] Barnett, E. and McKeown, L., 2012. The student behind the avatar: using second life for legal advocacy skills development and assessment for external students - A critical evaluation. Journal of Common Wealth Law and Legal Education, 8(2), pp. 44-63.

[15] Barton, D.L., 1988. Implementation Characteristics of Organizational Innovations: Limits and Opportunities for management strategies. Communication Research, 15(5), pp. 603631.

[16] Biemans, W.G., 1992. Managing Innovations with in Networks. New York: Routledge.

[17] Black, J.S. and Gregersen, H.B., 2003. Leading Strategic Change: Break through the Barrier. New York: Prentice Hall.

[18] Blacklock, J., Westley, F.R. and McGowan, K.A., 2016. How game changers catalyzed, disrupted and incentivized social innovation: Three historical cases of nature conservation, assimilation and women's rights. Ecology and Society, 21, pp. 4-13.

[19] Blumberg, B.F. and Pfann G.A., 2016. Roads leading to self-employment: Comparing Transgenerational entrepreneurs and self-mode startups. Entrepreneurship Theory and Practice, 40(2), pp. 335-357.

[20] Boonsiritomachai, W. and Pitchayadejanant, K., 2017. Determinants affecting mobile banking adoption by generation Y based on the Unified Theory of Acceptance and Use of Technology Model modified by Technology Acceptance Model Concept. Kasetsart Journal of Social Sciences, 1, pp. 1-10.

[21] Borghi, E., Avanzi, J., Bortolon, L. and Luchiari, A., 2016. Adoption and use of precision agriculture in Brazil: Perception of Growers and Service Dealership. Journal of Agriculture Science, 8(11), pp. 89-104.

[22] Bosque, I.R. and Herrero, A., 2008. Explaining B2C e-commerce acceptance: An Integrative Model based on the framework by Gatignon and Robertson. Interacting with Computers, 20(2), pp. 212-224.

[23] Botha, N. and Atkins, K., 2005. An assessment of five different theoretical framworks to study the uptake of innovations. In: New Zealand Agriculture and Resource Economic Conference Proceedings. Nelson, New Zealand, 26-27 August 2005. Nelson, New Zealand: New Zealand Agriculture and Resource Economics Society.

[24] Bredillet, C., Yatim, F. and Ruiz, P., 2010. Project Management deployment: The role of cultural factors. International journal of project management, 28, pp. 183-193.

[25] Brown, J.S., 2003. Open Innovation. Harvard: Harvard Business Review Press.

[26] Brown, T., 2009. Change by Design: How design thinking transforms organizations and inspires innovations. Canada: Haper Collins

[27] Carter, L. and Belanger, F., 2005. The utilization of e-government services: citizen trust, innovation and acceptance factors. Information Systems Journals, 15(1), pp. 5-25.

[28] Carter, L. and Weerakkody, V., 2008. E Government Adoption: A Cultural Comparison. Information Systems Frontiers, 10, pp. 473-482.

[29] Casalo, L.V., Flavian, C., Guinaliv, M., 2012. Determinants of the intention to participate in firm hosted online travel communities and effects on consumer behavior intentions. Tour management, 31, pp. 898-911.

[30] Caselli, F. and Coleman, W.J., 2001. Cross Country Technology Diffusion: The Case of Computers. The American Economic Review, 19(2), pp. 328-335.

[31] Castle, M.H., Lubben, B.B. and Luck, J.D., 2016. Factors influencing the adoption of precision agriculture technologies. Lincoln, USA: University of Nebruska Lincoln Press.

[32] Christia, J., 2000. The effects of alliance image on the relationship between consumer innovativeness and new product adoption. PhD. Oklahoma State University.

[33] Clemons, E.K., Gao, G.G. and Hitt, L.M., 2006. When online Reviews Meets Hyper Differentiation: A study of the Craft Beer Industry. Journal of Management Information Systems, 23(2), pp. 149-171. 

Attack Treatment. Cambridge: National Bureau of Economic Research.

[36] D Antonio, J.M., Mishra, M.A. and Joo, H., 2012. Farmers perception of precision technology: The case of auto seer adoption by cotton farmers. Computers and Electronics in Agriculture, 87, pp. 121-128.

[37] David, F.D., Davis, G.B., Venkatesh, V. and Morris, M., 2003. User Acceptance of Information Technology: Toward a unified view. MIS Quarterly, 27(3), pp. 425-478.

[38] Davis, F.D., Bagozzi, R.P. and Warshaw, P.R., 1989. User acceptance of computer technology: A comparison of two theoretical models. Management Science, 35, pp. 9821003.

[39] DeKempe, M.G., Parker, P.M. and Sarvary, M., 1998. Staged Estimation of International Diffusion Models: An application to global cellular telephone adoption. Technological forecasting and social change, 57(1), pp. 105-132.

[40] Designorate, 2017., Types of Innovation and how to utilize them. [Online] Available at: https://www.designorate.com/typesofinnovations/ > [Accessed 02 August 2018]

[41] Diederen, P., Meilj, H.V. and Wolters, A., 2003. Innovation adoption in agriculture: Innovators, early adopters and laggards. Cahlers d' Economie et de Sociologie Rurales, 67, pp. 29-50.

[42] Dimaggio, P.J. and Powell, W.W., 1983. The Iron Cage Revisited: Institutional Isomorphism and Collective Rationality in Organizational Fields. American Sociological Review, 48(2), pp. 147-160.

[43] Doblin, 2003., Ten Types of Innovation. [Online] Available at: $<$ https://www.doblin.com/dist/images $>$ [Accessed 02 August 2018]

[44] Dodds, W.B. and Monroe, K., 1991. Effects of Price, Brand and Store Information on Buyer's Product Evalaution. Journal of Marketing Research, 28(3), pp. 307-319.

[45] Downes, L. and Nunes, P., 2013. Big Bang Disruption. Harvard Business Review, 3, pp. 44-56.

[46] Ellison, G and Fudenberg, D., 1995. Word of Mouth Communication and Social learning. Quarterly Journal of Economics, 110, pp. 93-125.

[47] Epstein, J.L., Sanders, M.G. and Sheldon, S., 2009. School, Family and Community Partnerships: Your Hand book for action. CA: Corwie Press.

[48] Ferrero, G., 1984. Linertie mentale et la loi du moindre effort. Revue Philosophique de la France et de letranger, 37, pp. 169-182.

[49] Fraj, E. and Martinez, E., 2006. Environmental Values and Life Syles as determining factors of ecological consumer behavior: an empirical analysis. Journal of Consumer Marketing, 23(3), pp. 133-144.

[50] Frambach, R.T. and Schilleweart, N., 2002. Organizational Innovation Adoption: A MultiLevel framework of determinants and opportunities for future research. Journal of Business Research, 55(2), pp. 153-176.

[51] Gabrick, J., 2010. Step by Step Innovation. Morgan: MindMattters Press.

[52] Gabris, G.T., Ihrke, D. and Golembiewski, R.T., 2001. Leadership Credibility, Board Relations and Administrative Innovation at the Local Government Level. Journal of Public Administration Research and Theory, 12(1), pp. 89-108.

[53] Gatingnon, H. and Robertson, T., 1985. A Propositional Inventory for New Diffusion Research. Journal of Consumer Research, 11(4), pp. 849-867.

[54] Gelb, E. and Voet, H., 2009. ICT Adoption trends in agriculture: a summary of the EFITA ICT adoption questionnaires. EFITA Conference 2009 Proceedings, pp. 901-909.

[55] Gillispie, J.S., Kim, A. and Pandel, K., 2007. Why don't producers adopt best management practice? An analysis of the beef cattle industry. Agriculture Economics, 26, pp. 89-102. Gladwell, M., 2000. The Tipping Point. USA: Little, Brown and Company.

[58] Godinho, M.W. and Fagerberg, J., 2003. Innovation and Catching up. Oslo: Centre for Technology, Innovation and Culture, University of Oslo. 
Godoe, P. and Johansen, T.S., 2012. Understanding adoption of new technologies: Technology readiness and acceptance as an integrated concept. Journal of European Psychology Students, 3(1), pp. 38-52.

[60] Goldenberg, J., Libal, B., Soloman, S., Jan, S. and Stauffer, D., 2001. Marketing Percolation. Physica, 284(1), pp. 335-347.

[61] Gourville, J.J., 2006. Eager Sellers and Strong Buyers: Understanding the Psychology of New-Product Adoption. Harvard Business Review, 6, pp. 3-7.

[62] Gray, W.B. and Shadbegian, R.J., 1998. Environmental Regulation, Investment Timing and Technology Choice. The Journal of Industrial Economics, 46(2), pp. 235-256.

[63] Gregg, R.J., 1964. Scottish-Irish Urban Speech in Ulster. Ulster Dialects, 1, pp. 109-139.

[64] Gruber, H, and Verboven, F., 2001. The diffusion of mobile telecommunication services in the European Union. European Economic Review, 45(3), pp. 377-388.

[65] Gruber, H. and Verboven, F., 2000. The Diffusion of Mobile Telecommunications Services in the European Union. European Economic Review, 45(3), pp. 577-588.

[66] Gruner, K.E. and Hombury, C., 2000. Does Customer Interaction Enhances New Product Success? Journal of Business Research, 49(1), pp. 1-14.

[67] Guseo, R. and Mortarino, C., 2015. Modeling Competition between two pharmaceutical drugs using innovation diffusion models. The Annals of Applied Statistics, 9(4), pp. 207220.

[68] Harvey, L.D., 2009. Reducing energy use in the building sector: measures, costs and examples. Energy Efficiency, 2, pp. 139-163.

[69] Haynes, J.D., 2009. Perspective thinking for Inquiring Urbanization. Communications of ACM, 52, pp. 7-30.

[70] Health Catalyst, 2018. Health Care Analytics Adoption Model. [Online] Available at: $<$ https://www.healthcatalyst.com/health-analytics-adoption-models/> [Accessed 05 February 2018]

[71] Helsen, K., Jedidi, K. and Desarbo, W.S., 1993. A New approach to country segmentation utilizing multinational diffusion pattern. Journal of Marketing, 57(10), pp. 60-71.

[72] HIMSS Analytics, 2018. Electronic Medical Record Adoption Model. [Online] Available at: <https://www.himssanalytics.org/emram> [Accessed 05 March 2018]

[73] Hirschman, E.C., 1980. Innovativeness, Novelty Seeking and Consumer Creativity. Journal of Consumer Research, 7(3), pp. 283-295.

[74] Hodas, N.O. and Lerman, K., 2014. The simple rules of social contagion. Sci. Rep., 4, pp. 43-54.

[75] Hudson, D. and Hite, D., 2003. Adoption of Precision Agriculture Technology in Mississippi. Mississipi: Mississipi State University Press.

[76] Joshi, A.W. and Sharma, S., 2004. Customer Knowledge Development: Antecedents and Impact on New Product Performance. Journal of Marketing, 68(4), pp. 47-59.

[77] Kaine, G., Beswell, D. and Linehan, C., 2004. Value Challenging Innovation in Agriculture. Victoria, Australia: Department of Primary Industries.

[78] Kaipa, P., 2012. What wise leads follow? Harvard Business Review Blog, [Blog] 18 January. Available at: $<$ http://karpagroup.com/articles/four questions/four questions.pdf $>$ [Accessed 01 September 2018]

[79] Kekana, G., Aigbavboa, C. and Thwala, W., 2015. Understanding Building Modeling in the Southern Africa Construction Industry. Johannesburg: University of Johannesburg Press.

[80] Keller, J.M. and Suzuki, K., 1988. Use of ARCS motivation model in course ware design. In: D.H. Jonassen, ed. 1988. Instructional Design for Micro Computer Usage. Hillsade NJ: Lawrance Erlbaum.

[81] Kirton, M., 1976. Adaptor and Innovator. A description and measure. Journal of Applied Psychology, 61(5), pp. 622-629.

[82] Kwan, S.K. and Min, J.H., 2008. An evolutionary framework of services systems. Journal of Harbin Institute of Technology, 15(1), pp. 1-7.

[83] Lehman, D.R. and Weinberg, C.B., 2000. Sales through sequential distribution channels: an application to movies and videos. Journal of Marketing. 64(3), pp. 18-33. 
[100] Morgan, R.M. and Hurt, S.D., 1994. The Commitment - Trust Theory of Relationship Marketing. Journal of Marketing, 58(3), pp. 20-38.

[101] Mowery, D. and RosenBerg, N., 1979. The influence of market demand upon Innovation: a critical review of some recent empirical studies. Research Policy, 8(2), pp. 102-153.

[102] Mullaly, M. and Thomas, J., 2008. Researching the value of project management. Pennslyvania: Project Management.

[103] Ngambi, D. and Bozalek, V., 2013. Leveraging Informal leadership in higher education institutions: A case of diffusion of emerging technologies in a Southern context. British Journal of Educational Technology, 44(6), pp. 940-950.

[104] Nkegbe, P.K. and Shankar, B., 2014. Adoption intensity of soil and water water conservation practices by small holders: evidence from Northern Ghana. Bio- Based and Applied Economics, 3(2), pp. 159-174.

[105] Norris, C.A. and Soloway, E., 2011. Learning and Schooling in the age of Mobilism. Educational Technology, 11, pp. 3-10.

[106] Obrecht, A., Warner, A. and Dillon, N., 2017. Evaluating Humanitarian Innovation. London: ALNAP

[107] OECD, 2005. The OECD Innovation Strategy - 2015 Revision. [Online] Available at: $<$ www.oecd.org/innovation/innovation-imperative. htm > [Accessed 02 February 2018]

[108] Oliver, P.E. and Myers D.J., 2001. The Co-evolution of social movements. Mobilization: An International Journal, 8(1), pp. 1-24. 
[109] Oster, E. and Thornton, R., 2010. Determinants of Technology adoption: Peer effects in Menstrual Cup Take up. Journal of the European Economic Association, 10(6), pp. 12631293.

[110] Parasuraman, A., 2000. Technology Readiness Index: A multiple Item scale to measure readiness to embrace new technologies. Journal of Service Research, 2(4), pp. 307-320.

[111] Parker, P.M., and Roller, L.H., 1997. Collusion conduct in Oligopolies. Multimarket contact and cross ownership in the mobile telephone industry. RAND Journal of Economics, 28(2), pp. 304-322.

[112] Parmentola, A., Somoni, M. and Tutore, I., 2018. Fast and Furious: how the open Vs closed dilemma affects the technology diffusion dynamics. Management Decision, 56(4), pp. 867890.

[113] Paudel, K., Pandit, M., Mishara, A. and Segarra, E., 2011. Why don't farmers adopt precision farming technologies in cotton production? In: 2011 Agricultural and Applied Economics Association Annual meeting. Pittsburg, 24-26 July 2011. Pennsylvania: Agriculture and Applied Economics Association.

[114] Pavlou, P.A., 2003. Consumer acceptance of Electronic Commerce: Integrating Trust and Risk with the TAM. International Journal of Electronic Commerce, 59(4), pp. 69-103.

[115] Payne, A., 2014. Deconstructing the value proposition of an innovation exemplar. European Journal of Marketing, 48(1-2), pp. 237-270.

[116] Peirpaoli, E., Carli, G., Pignatti, E. and Canavari, M., 2013. Drivers of Precision Agriculture Technologies Adoption: A Literature Review. Procedia Technology, 8, pp. 61-69.

[117] Perez, G., Popadick, S. and Cesar, A., 2017. Internal factors that favor the adoption of technological innovation defined by information systems: A study of the Electronic Health Record. Innovation and Management Review, 14(1), pp. 67-78.

[118] Pifeffer, J. and Salancik, G.R., 1978. The external control of organization: A resource dependence perspective. New York: Harper and Row.

[119] Pignatti, E., Carli, G. and Canavari, M., 2015. What really matters? A Qualitative analysis on the adoption of innovations in agriculture. Journal of Agriculture Information, 6(4), pp. 73-84.

[120] Porter C.E. and Donthu, N., 2006. Using the TAM to explain how attitudes determine internet usage. Journal of Business Research, 59(9), pp. 999-1007.

[121] Prochaska, J.O. and Dialemeote, C.C. and Norcross, J.C., 1992. In search of how people change? American Psychologist, 47, pp. 1102-1114.

[122] Puentedura, R.R., 2006. Learning, Technology and the SAMR Model: Goals, Processes and Practice. Review of Educational Research, 76(3), pp. 40-62.

[123] Pyzalska, K., 2018. What makes consumers adopt innovative energy services in the energy market? A review of incentives and barriers. Renewable and Sustainable Energy Reviews, 82(P3), pp. $357-368$.

[124] Rachel, G., Rupert, H. and Garett, M., 2006. Product Market Reforms, Labor Market Institutions and Unemployement. CEPR Discussion Papers, 5599.

[125] Randall, L.M. and Coakley, L.A., 2007. Applying adaptive leadership to successful change initiatives in academia. Leadership and Organizational Development Journal, 28(4), pp. 325-335.

[126] Rangaswamy, A. and Gupta, S., 2000. Innovation adoption and diffusion in the digital environment, some research opportunities. Boston: Kluwer Academic Publishers.

[127] Reichardt, M. and Jurgen, C., 2009. Adoption and Perspective of Precision farming in Germany: Results of several surveys among the different agricultural target groups. Precision Agriculture, 10(1), pp. 73-94.

[128] Robertson, T.S., 1967. The process of Innovation and the Diffusion of Innovation. Journal of Marketing, 31(1), pp. 14-19.

[129] Rogers, E.M., 1983. Diffusion of Innovations (3rd ed). New York: Free Press of Glencoe. Ruyter, K.D., Wetzels, M. and Kleijnen, M., 2001. Customer adoption of e-services: an empirical study. Marketing Letters, 15(1), pp. 21-36. 
[130] Sandia, 2004. Sandia Research. [pdf] Sandia. Available at: $<$ https://sandia.gov/research /assests/documents/sandiaresearchvol2_Iss2.pdf > [Accessed 20th April 2018]

[131] Sawhney, M., Verona, G. and Prandelli, E., 2005. Collaborating to create: The internet as a platform for customer engagement in product innovation. Journal of Interactive Marketing, 19(4), pp. 4-17.

[132] Schmidt, G.M. and Druchl, C.T., 2005. Changes in Product Attributes and Cost as Drivers of New Product Diffusion and Substitution. Product and Operations Management, 14, pp. 272-285.

[133] Schmidt, G.M. and Porteus, E.L., 2000. The impact of an integrated marketing and manufacturing innovation. Manufacturing and service operations management. 2(4), pp. 415-423.

[134] Shane, S., 2008. The Hand Book of Technology and Innovation Management. New York: Wiley-Black Well.

[135] Shapiro, C. and Katz, M., 1985. On the Licensing of Innovations. RAND Journal of Economics, 16(4), pp. 504-520.

[136] Shapiro, C. and Varian, H.R., 1999. Information Rules: A Strategic Guide to the Network Economy. Harvard: Harvard Business School Press.

[137] Shy, O., 1996. Industrial Organizations: Theory and Application. Cambridge: MIT Press.

[138] Silva, V., Lira, M. and Pereira, V., 2001. Nutritive Value and Voluntary intake of rubber bush. Pasturas Tropicales, 23(2), pp. 20-23.

[139] Spears, L.C., 2005. The understanding and practice of servant leadership. International Journal of Servant Leadership, 1(1), pp. 29-46.

[140] Sprott, J.C., Wildenberg, J.C. and Azizi, Y., 2005. A simple Spatio-temperoral chaotic Lokta-Volterra model. Chaos, Solitons and Fractals, 26, pp. 1035-1037.

[141] Statnikova, K.N., 2005. Information Technology: What works and what does not? M Tech. Vanderbist University.

[142] Stauffer, D. and Aharony, A., 1994. Introduction to Percolation Theory. Stockholm: Taylor and Francis.

[143] Stone, D., 2002. Policy Paradox: The Art of Political Decision Making. New York: W.W. Norton

[144] Stoneman, P. and Diederen, P., 1994. Technology Diffusion and Public Policy. Economic Journal, 104, pp. 918-930.

[145] Strang, D. and Macy, M.W., 2001. In Search of Excellence, Fads, Success stories and Adaptive emulation. American Journal of Sociology, 107(1), pp. 147-182.

[146] Sun, B., Neslin, S.A. and Srinivasan, K., 2003. Measuring the impact of promotions on brand switching when consumers are forward looking. Journal of Marketing Research, 40(4), pp. 389-405.

[147] Sykes, T.A., Venkatesh, V. and Gosain, S., 2009. Model of Acceptance with peer support. A social network perspective to understand employer's system use. MIS Quarterly, 32(2), pp. 371-393.

[148] Takada, H. and Jain, D.C., 1991. Cross National Analysis of Diffusion of Consumer Durable Goods in Pacific Countries. Journal of Marketing, 55(2), pp. 48-60.

[149] Talukder, M., Haron, H. and Mapunda, G., 2012. Adoption of Innovation by Individuals with in Organizations: An Australian study. Asia Pacific Management Review, 13(2), pp. 463-480.

[150] Tellis, G.J. and Stremersch, S., 2002. Strategic Bundling of Products and Prices: A New Synthesis for Marketing. Journal of Marketing, 66(1), pp. 55-72.

[151] Teng, T.C., Grover, V. and Gutter, V., 2002. Information Technology Innovation: General Diffusion Pattern and Its relationship to Innovation Characteristics. IEEE Transaction on Engineering Management, 49, pp. 13-27.

[152] Tey, Y.S. and Brindal, M., 2012. Factors influencing the adoption of precision agricultural technologies. A review for policy implication. Precision Agriculture, 13, pp. 713-730.

[153] Thompson, R.L. and Baril, W.C., 2009. Information Technology and Management. New York: Mc Graw - Hill/Irwin.

[154] Toffler, A., 1970. Future Shock. USA: Penguin Random House LLC. 
[155] Tohidyan, S and Moghaddam, F.R., 2015. Attitudes of farmers towards participation in irrigation and drainage projects. The Iran Agriculture Research, 34(1), pp. 80-91.

[156] Tung, L.L. and Rieck, O., 2005. Adoption of Electronic Government Services among business organizations in Singapore. Journal of Strategic Information Systems, 14, pp. 417440.

[157] Varian, H. and Choi, H., 2012. Predicting the present with Google trends. Economic Record, 88(1), pp. 2-9.

[158] Venkatesh, V. and Davis, F.D., 2000. A Theoretical Extension of the TAM: For longitudinal field studies, Management Science, 46(2), pp. 169-332.

[159] Vogel, C.M., 2014. Notes on the evolution of the design thinking. A work in progress. Design Management Review, 20(2), pp. 16-27.

[160] Vries, H.D., Bekkers, V. and Tummers, L., 2015. Innovation in the public sector: A Systematic Review and Future Research Agenda. Public Administration Quarterly, 94(1), pp. 146-168.

[161] Wang, J. and Li, C., 2010. Licensing a Vertical Product Innovation. Economic Record, 86, pp. 603-631.

[162] Wang, W.H. and Liu, Y.J., 2009. Attitude, Behavioral Intention and Usage: An Empirical study of Taiwan Railway's internet ticketing system. Taiwan: National Taiwan Ocean University.

[163] Wangenheim, F.V. and Bayon, T., 2007. Behavioral Consequences of Overbooking Service Capacity. Journal of Marketing, 71(4), pp. 36-47.

[164] Wareham, J., Levy, A. and Shi, W., 2004. Wireless Diffusion and Mobile Computing: Implications for the Digital Divide. Telecommunication Policy, 28(5), pp. 439-457.

[165] Warkentin, M., Gefen, D., Pavlou, P. and Rose, G., 2002. Encouraging Citizen Adoption of e-government by building trust. Electronic Markets, 12, pp. 157-162.

[166] Watcharaanantapong, P., Lambert, D.M. and Roberts, R.K., 2014. Timing of Precision Agriculture Technology adoption in US Cotton production. Precision Agriculture, 15(4), pp. 427-446.

[167] Wedel, M. and Kamakura, W.A., 1999. Market Segmentation: Conceptual and Methodological Foundations, Dordrecht: Kluwer.

[168] Wells, W. and Tigret, D., 1971. Activities, Interests and Opinions. Journal of Advertising Research, 11(4), pp. 27-35.

[169] Wenger, E., White, N. and Smith, J.D., 2009. Digital Habitats: Stewarding Technology for Communities. Portland: CPsquare.

[170] Wiefels, P., 2002. The Chasm Companion: A Field guide to crossing the chasm and inside the tornado. New Jersy: Wiley and Sons.

[171] Yang, H.D. and Yoo, Y., 2004. It's all about attitude: Revisiting the TAM. Decision Support Systems, 38(1), pp. 19-31.

[172] Yoon, E. and Tello, S.F., 2008. Examining drivers of sustainable innovation. International Journal of Business Strategy, 8(3), pp. 164-169.

[173] Zhang, X., Yu, P. and Spil, T.A., 2015. Using diffusion of innovation theory to understand the factors impacting patient acceptance and usage of consumer e-health innovations: a case study in a primary care clinic. BMC Health Services Research, 15, pp. 71-80. 